\title{
Supplementary Eye Field during Visual Search: Salience, Cognitive Control, and Performance Monitoring
}

\author{
Braden A. Purcell, Pauline K. Weigand, and Jeffrey D. Schall \\ Department of Psychology, Center for Integrative \& Cognitive Neuroscience, and Vanderbilt Vision Research Center, Vanderbilt University, Nashville, \\ Tennessee 37240
}

How supplementary eye field (SEF) contributes to visual search is unknown. Inputs from cortical and subcortical structures known to represent visual salience suggest that SEF may serve as an additional node in this network. This hypothesis was tested by recording action potentials and local field potentials (LFPs) in two monkeys performing an efficient pop-out visual search task. Target selection modulation, tuning width, and response magnitude of spikes and LFP in SEF were compared with those in frontal eye field. Surprisingly, only $\sim 2 \%$ of SEF neurons and $\sim 8 \%$ of SEF LFP sites selected the location of the search target. The absence of salience in SEF may be due to an absence of appropriate visual afferents, which suggests that these inputs are a necessary anatomical feature of areas representing salience. We also tested whether SEF contributes to overcoming the automatic tendency to respond to a primed color when the target identity switches during priming of pop-out. Very few SEF neurons or LFP sites modulated in association with performance deficits following target switches. However, a subset of SEF neurons and LFPs exhibited strong modulation following erroneous saccades to a distractor. Altogether, these results suggest that SEF plays a limited role in controlling ongoing visual search behavior, but may play a larger role in monitoring search performance.

\section{Introduction}

Natural vision requires an organism to select important objects from irrelevant objects to guide responses. Models of visual search propose that a salience map (also termed "priority") combines bottom-up physical conspicuousness with top-down knowledge of target features to guide attention and eye movements (Tsotsos et al., 1995; Itti and Koch, 2001; Bundesen et al., 2005; Wolfe, 2007). A distributed network of visuomotor areas encodes a representation of salience (Findlay and Walker, 1999; Thompson and Bichot, 2005; Gottlieb, 2007; Bisley and Goldberg, 2010). This includes the frontal eye field (FEF) (Thompson et al., 1996; Bichot and Schall, 1999; Purcell et al., 2012), superior colliculus (SC) (McPeek and Keller, 2002; Shen and Paré, 2007), substantia nigra pars reticulata (SNpr) (Basso and Wurtz, 2002), lateral intraparietal area (LIP) (Ipata et al., 2006; Thomas and Paré, 2007; Balan et al., 2008; Arcizet et al., 2011) and parietal area 7A (Constantinidis and Steinmetz, 2001). Supplementary eye field (SEF) receives cortical afferents from FEF, LIP, and 7A (Andersen et al., 1990; Huerta and Kaas, 1990; Schall et al., 1993) as well as from the superior temporal polysensory (STP) area and nuclei in the central thalamus that are innervated by SC and SNpr

Received Dec. 21, 2011; revised June 1, 2012; accepted June 6, 2012.

Author contributions: B.A.P. and J.D.S. designed research; B.A.P. and P.K.W. performed research; B.A.P. analyzed data; B.A.P. and J.D.S. wrote the paper.

This work was supported by National Institutes of Health Grants T32-EY07135, R01-EY08890, American Recovery and Reinvestment Act (ARRA) supplement R01-EY08890-19S2, P30-EY008126, and P30-HD015052; and by Robin and Richard Patton through the E. Bronson Ingram Chair in Neuroscience.

The authors declare no financial conflicts of interest.

Correspondence should be addressed to Dr. Jeffrey D. Schall, Department of Psychology, Vanderbilt University, PMB 407817, 2301 Vanderbilt Place, Nashville, TN 37240-7817. E-mail: jeffrey.d.schall@vanderbilt.edu.

DOI:10.1523/JNEUROSCI.6386-11.2012

Copyright $\odot 2012$ the authors $\quad 0270-6474 / 12 / 3210273-13 \$ 15.00 / 0$
(Lynch et al., 1994; Parent and Hazrati, 1995) and contribute to saccade target selection (Schall and Thompson, 1994; Wyder et al., 2004) (Fig. 1).

Connectivity with these visuomotor areas suggests that SEF may represent just one more node in the cortical network representing salience. Furthermore, SEF neurons exhibit clear visual responsiveness (Schlag and Schlag-Rey, 1987; Schall, 1991a,b; Russo and Bruce, 2000; Pouget et al., 2005). SEF neurons respond selectively to a number of stimulus categories including the type of information they provide (Campos et al., 2009), arbitrary stimulus response associations (Chen and Wise, 1995a,b, 1996; Olson and Tremblay, 2000; Olson et al., 2000), expected reward (Seo and Lee, 2009; So and Stuphorn, 2010), and their rank order in a sequence (Lu et al., 2002; Berdyyeva and Olson, 2009). However, similarity of elementary physiological properties may belie important functional differences in more complex contexts; for example, although many neurons in FEF, SC, and SEF discharge before saccades, saccade initiation is directly controlled by FEF (Hanes and Schall, 1996; Hanes et al., 1998) and SC (Paré and Hanes, 2003), but not SEF (Schiller et al., 1979; Schiller and Chou, 1998; Stuphorn et al., 2010).

Other research suggests that medial frontal areas, including $\mathrm{SEF}$, are involved in the monitoring and control processes recruited when errors are made and habitual actions must be overcome (for review, see Schlag-Rey et al., 1997; Stuphorn et al., 2000; Stuphorn and Schall, 2006; Isoda and Hikosaka, 2007; Emeric et al., 2010; Isoda and Hikosaka, 2011). Priming of popout tasks in which the target and distractor features switch randomly every few trials requires overcoming the primed tendency to respond to a distractor following switches (Maljkovic and $\mathrm{Na}$ kayama, 1994; Bichot and Schall, 1999). FEF neurons that encode 


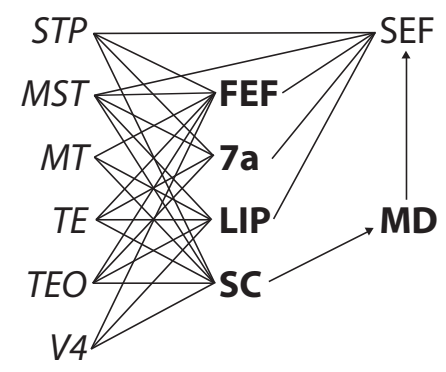

Figure 1. Distribution of visual afferents to SEF. Lines indicate reciprocal connections. Arrow indicates one-way projection. SEF is densely connected with visuomotor areas that are known to represent visual salience (bold) including FEF and LIP, area 7a, as well as from SC via the medial dorsal nucleus of the thalamus (MD). These areas receive afferents from diverse areas in visual cortex that encode various target features (italicized). In contrast, SEF does not receive direct input from areas representing stimulus features from which a salience map is computed. Not pictured are efferent connections to $\mathrm{SC}$ and reciprocal connections with the ventral anterior and ventrolateral nuclei of the thalamus which are innervated by substantia nigra pars reticulata.

salience modulate in parallel with changes of performance during priming (Bichot and Schall, 2002), but it is not known whether medial frontal cortex is involved in suppressing the primed tendency to respond to a distractor or facilitating the controlled response to the new target.

We tested the hypothesis that SEF encodes visual salience to select saccade targets by recording spiking activity and local field potentials (LFPs) in the SEF of two monkeys trained to perform a visual search task. We also asked whether SEF controls or monitors changes in performance during priming of pop-out. The data also provide new quantitative comparisons between SEF and FEF.

\section{Materials and Methods}

\section{Behavioral tasks and recordings}

Recording procedure. We recorded neuronal spikes and simultaneous LFPs from the SEF of one male bonnet macaque monkey (Macaca radiata, $\sim 8.5 \mathrm{~kg}$, monkey F) and one male rhesus macaque monkey (Macaca mulatta, $\sim 12.5 \mathrm{~kg}$, monkey Z). Monkeys were surgically implanted with a head post and recording chambers during aseptic surgery with animals under isoflurane anesthesia. Antibiotics and analgesics were administered postoperatively. All surgical and experimental procedures were in accordance with the National Institute of Health Guide for the Care and Use of Laboratory Animals and approved by the Vanderbilt Institutional Animal Care and Use Committee.

Neurons and LFPs were recorded simultaneously from the right hemisphere of both monkeys using tungsten microelectrodes (2-4 M $\Omega$, FHC) and were referenced to a guide tube in contact with the dura. Spikes were sampled at $40 \mathrm{kHz}$, and LFPs were sampled at $1 \mathrm{kHz}$. LFPs were bandpass filtered between 0.2 and $300 \mathrm{~Hz}$ and were amplified using a Plexon HST/ 8o50-G1 head-stage. A $60 \mathrm{~Hz}$ second-order IIR notch filter was applied off-line to reduce electrical noise. LFPs were baseline corrected using the average voltage $50 \mathrm{~ms}$ until the array onset. Spikes were sorted on-line using a time-amplitude window discriminator and off-line using principal component analysis and template matching (Plexon). We generated spike density functions by convolving each spike train with a kernel resembling a postsynaptic potential (Thompson et al., 1996). Eye movements were monitored with an infrared corneal reflection system (SR Research) at a sampling rate of $1 \mathrm{kHz}$.

Behavioral tasks. Monkeys were trained to perform three tasks: a visual search task, a detection task, and a memory-guided saccade task (Fig. 2). Tasks were run in blocks, and task order was counterbalanced across recording sessions. All tasks began with the monkey fixating a central white spot for $\sim 500 \mathrm{~ms}$. In the color visual search task, the fixation point changed from filled to open simultaneously with the onset of a colored target and seven isoluminant distractors $\left(2.8 \mathrm{~cd} / \mathrm{m}^{2}\right)$ of the opposite

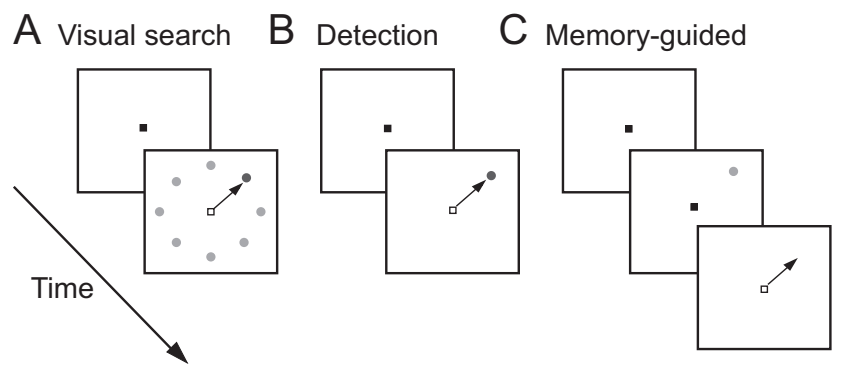

Figure 2. A, Visual search task. After fixating a central point for a variable delay (top frame), an array of stimuli was presented (bottom frame), one of which was the target (e.g., dark gray disk) and the rest were distractors (e.g., light gray disks). Monkeys were required to make a single saccade (indicated by the arrow) to the target for reward. $\boldsymbol{B}$, Detection task. This task is identical to the visual search task except the target appeared alone without distractors. $C$, Memory-guided saccade task. After fixating for a variable delay (top frame), the target was flashed for $100 \mathrm{~ms}$ at one of eight locations (middle frame). The animal was required to maintain fixation for a variable delay until the fixation point changed from filled to open (bottom frame), which signaled the animal to make a single saccade to the remembered target location for reward.

color. Targets and distractors were either red [Commission International de l'Eclairage (CIE) chromaticity coordinates $x=0.648, y=0.331$ ] or green (CIE chromaticity coordinates $x=0.321, y=0.598$ ). The monkey was rewarded for making a single saccade to the location of the target within $2000 \mathrm{~ms}$ and fixating for $500 \mathrm{~ms}$. For some experimental sessions, target and distractor color remained constant throughout the session and target color was varied across sessions. For other sessions, target and distractor color were swapped in successive blocks of trials to investigate priming of pop-out. Block duration was sampled from a uniform distribution ranging over $8-16$ trials. This task required animals to discriminate the singleton target from distractors and then shift gaze to that location as quickly as possible while maintaining reasonable accuracy.

In the detection task, the target (red or green disk) was presented at one of the same eight locations and remained on the screen. Simultaneous with the onset of the target, the fixation point changed from filled to open, instructing the animal to make a saccade to the target location within $2000 \mathrm{~ms}$ and maintain fixation for $500 \mathrm{~ms}$ for reward. This task was identical to the visual search task, but included no distractor stimuli.

In the memory-guided saccade task, a target (filled gray disk) was presented for $100 \mathrm{~ms}$ at one of eight isoeccentric locations equally spaced around the fixation spot at $10^{\circ}$ eccentricity. The animal was required to maintain fixation for $400-800 \mathrm{~ms}$ (uniform distribution) after the target onset. After the fixation point changed from filled to open, the monkeys were rewarded for making a saccade to the remembered location of the target and maintaining fixation for $500 \mathrm{~ms}$. For monkey Z, this task also included a small fraction $(\sim 15 \%)$ of "NoGo trials" in which a change in fixation point color cued the monkey to maintain fixation for reward. The memory-guided saccade task was used to temporally dissociate sensory and motor-related responses for neuron and LFP classification (Bruce and Goldberg, 1985).

Localization of SEF. In both monkeys, we determined the location of SEF by the effects of intracortical microstimulation and histology (Fig. $3)$. Microstimulation parameters were conventional (100 ms trains of $333 \mathrm{~Hz}$ biphasic pulses of $0.2 \mathrm{~ms}$ pulse duration). After the experiment, monkey F was deeply anesthetized with pentobarbital and perfused with $0.1 \mathrm{~m}$ PBS, followed by $4 \%$ paraformaldehyde (PFA) in PBS followed by buffered sucrose solution (10\% sucrose, $4 \%$ PFA in PBS). Monkey Z could not be perfused, so the brain was post-fixed in 4\% PFA for $10 \mathrm{~d}$. Both brains were photographed in situ. Fiduciary guide pins in the recording chamber were located relative to the hemisphere midline and arcuate and principal sulci. Frozen sections $50 \mu \mathrm{m}$ thick were stained for Nissl substance. The sites of neurons and LFPs with task-related responses and sites from which saccades could be elicited with low threshold $(\leq 50 \mu \mathrm{A})$ microstimulation were located in Nissl-stained sections relative to previously described cytoarchitectural landmarks (Mitz and Wise, 1987; Luppino et al., 1991; Matelli et al., 1991; Schall, 1991a). 
A
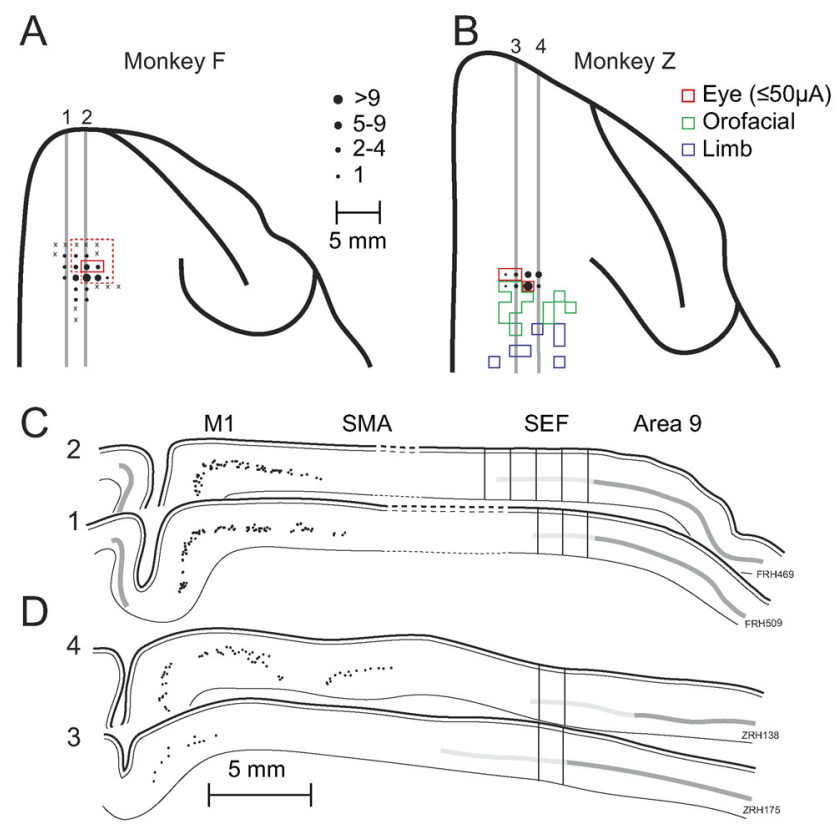

Figure 3. Localization of SEF. $\boldsymbol{A}, \boldsymbol{B}$, Dorsal view of recording sites in monkey $F(\boldsymbol{A})$ and monkey $Z(\boldsymbol{B})$. Circle size indicates the number of neurons with task-related responses. $X$ s indicate sites that were sampled, but no task-related neuron was found. Solid colored lines indicate areas in which limb, orofacial, and saccadic eye movements were elicited by electrical microstimulation. Red dashed lines indicate areas in which low threshold saccades were elicited at the symmetric position in the opposite hemisphere. $C$, Sagittal sections from monkey $F$ at levels indicated in $\boldsymbol{A}$ (gray lines 1 and 2) illustrate location of penetrations relative to cytoarchitectural landmarks. Black vertical lines indicate reconstructed penetration locations. The caudal penetration ( $\boldsymbol{C}$, curve 2 , left) is $27 \mathrm{~mm}$ anterior to the interaural line. Curves 1 and 2 in $\boldsymbol{C}$ are $\sim 4.7$ and $\sim 6.7 \mathrm{~mm}$ lateral of midline, respectively. Dots mark locations of Betz cells in primary motor cortex (M1) and supplementary motor area (SMA). Dark shading indicates granular layer in prefrontal cortex (area 9) and light shading indicates the incipient granular layer that is characteristic of SEF. Dashed lines indicate a damaged region. $\boldsymbol{D}$, Sagittal sections from monkey $Z$ at levels indicated in $\boldsymbol{B}$ (gray lines 3 and 4). Curves 3 and 4 in $\boldsymbol{C}$ are $\sim 6.0$ and $\sim 8.0 \mathrm{~mm}$ lateral of midline, respectively. Conventions are as in $\boldsymbol{C}$.

Frontal eye field data. We analyzed FEF neurons and LFPs recorded during the same visual search task to compare directly with SEF. We analyzed single-unit activity and LFPs recorded in the FEF of two additional monkeys (monkey Q, Macaca radiata, $\sim 7.5 \mathrm{~kg}$; monkey S, Macaca radiata, $\sim 8.5 \mathrm{~kg}$ ) during a color visual search task. This task included a set size manipulation in which the number of distractors $(1,3$, or 7$)$ varied randomly across trials, but was otherwise identical to the visual search task described above. We also analyzed previously published single-unit activity recorded from the FEF of monkey $\mathrm{F}$ while he performed the identical color search task (Sato et al., 2001). All FEF recordings were acquired from the rostral bank of the arcuate sulcus at sites where saccades were evoked with low-intensity electrical microstimulation $(<50 \mu \mathrm{A}$; Bruce et al., 1985). Analytical methods were identical for SEF and FEF data.

Behavioral performance was consistent across species. There was no systematic difference in percentage correct (87\% for monkey F: $85 \%$ for monkey Z; 96\% for monkey Q; 86\% for monkey S) or mean response time (RT) (210 ms for monkey F; $216 \mathrm{~ms}$ for monkey Z; $222 \mathrm{~ms}$ for monkey Q; 254 ms for monkey S).

\section{Data analysis}

Neuron and LFP classification. We identified task-related neurons and LFPs by comparing discharge rates or voltage to the baseline period $50 \mathrm{~ms}$ before presentation of the array. A neuron or LFP site was classified as visually responsive if discharge rate or polarization remained significantly different from baseline for five consecutive $10 \mathrm{~ms}$ time bins in the interval 50-200 ms following stimulus presentation for the memoryguided saccade task and in the interval $50-150 \mathrm{~ms}$ for the detection or search tasks (Wilcoxon rank-sum test, $p<0.05$ ). A neuron or LFP site was classified as saccade related if discharge rate or polarization remained significantly different from baseline for five consecutive $10 \mathrm{~ms}$ time bins in the interval $-100-100$ ms relative to saccade initiation for all tasks. Only visually responsive neurons are included in our analyses of visual salience, although we verified that results were identical for neurons with saccade-related discharge modulation. As in previous reports, many saccade-related neurons did exhibit direction selectivity, but it emerged too late to represent a covert salience representation that guided saccade target selection ( $<20 \mathrm{~ms}$ before saccade onset; Scudder et al., 2002; Stuphorn et al., 2010). All neurons were included in our priming analyses regardless of when task-related modulations were observed.

Spatial selectivity. The selectivity of spikes and LFPs to target location was quantified by vector summation of the normalized response to each target (Batschelet, 1981; Schall, 1991a). The angle of the resultant vector gave the preferred response location of the neuron or LFP site $\left(0^{\circ}\right.$, ipsilateral; $180^{\circ}$, contralateral). The length of the resultant vector was defined as the direction bias. Direction bias ranged from 0 (equal responses for all locations) to 1 (maximal response to a single location). When measured during the detection task with a single stimulus, this quantified the location and tuning width of the receptive field (RF) for a given eccentricity. When measured during the visual search task, this quantified the extent to which the target was localized. For visual search and detection, we used the average voltage or discharge rate from $50 \mathrm{~ms}$ after stimulus presentation until $50 \mathrm{~ms}$ before mean saccade initiation time to exclude saccade-related responses. For the memory-guided saccade task, we used the average voltage or discharge rate in the time interval from 50 to 200 $\mathrm{ms}$ after stimulus onset. We assessed the significance of spatial selectivity using a permutation test that determined the probability of obtaining the preferred location by chance alone (Georgopoulos et al., 1988; 1000 simulations, $p<0.01$ ).

We also quantified the selectivity of SEF and FEF neurons and LFPs to the target versus distractors using a "neuron-antineuron" analysis (Thompson et al., 1996). We computed the area under the receiver operating characteristic (ROC) curve from the distribution of discharge rate or polarization in trials in which the target appeared inside the RF and trials in which only distractors appeared inside the RF. The area under the curve reflects the probability that an ideal observed could correctly specify whether the target was in the neuron's RF. For this analysis, the RF was conservatively defined as the stimulus locations within $45^{\circ}$ of the preferred angle, although tuning width was also measured more rigorously (see Spatial tuning width). For neurons, the ROC was computed by incrementing a criterion from 0 spikes/s to the maximum discharge rate observed across all trials in steps of 1 spike/s. For LFPs, the criterion was incremented from the minimum voltage observed to the maximum voltage observed in steps of $10 \mu \mathrm{V}$. The distribution of discharge rates and voltages was obtained for $5 \mathrm{~ms}$ intervals averaged from $5 \mathrm{~ms}$ before to $5 \mathrm{~ms}$ after each time point to smooth the data. The average area under the ROC curve from $50 \mathrm{~ms}$ after array onset to 50 ms before mean RT determined the magnitude of target selectivity for each neuron and LFP site.

Visual response latency. The latency of the visual response was determined by comparing baseline activity $10 \mathrm{~ms}$ before array onset to a millisecond-by-millisecond sliding window starting at array onset. The visual onset was the time when activity first became significantly different from baseline and remained significant for 10 consecutive ms (Wilcoxon rank-sum test, $p<0.01$ ).

Spatial tuning width. We quantified the spatial tuning width by fitting the variation in discharge rate or voltage as a function of target location with a Gaussian function of the form:

$$
A(\varphi)=B+R \times \exp \left(-\frac{1}{2}\left[\frac{\varphi-\Phi}{T_{\varphi}}\right]^{2}\right)
$$

where activation $(A)$ as a function of meridional direction $(\varphi)$ depends on the baseline discharge rate $(B)$, maximum discharge rate $(R)$, optimum direction $(\Phi)$, and directional tuning $\left(T_{\varphi}\right)$ (Bruce and Goldberg, 1985; Schall et al., 1995b; Russo and Bruce, 2000; Schall et al., 2004; Monosov et al., 2008). Tuning width was estimated by the $\mathrm{SD}\left(T_{\varphi}\right)$ of the 
best fitting Gaussian curve. The data were fitted with a Simplex routine implemented in MATLAB (The MathWorks) to minimize the sum of squared deviations between observed and predicted values. We excluded neurons and LFP sites for which the Gaussian curve accounted for $<50 \%$ of the variance in the data indicating very poor fit ( 8 neurons; 26 LFPs). The eccentricity was matched for SEF and FEF recordings, which allows for direct comparison across areas and signals, but note that the tuning width of SEF and FEF neurons will vary with eccentricity (Bruce and Goldberg, 1985; Russo and Bruce, 2000).

Visual response magnitude. The magnitude of the initial visual response in SEF neurons and LFP was computed as the mean discharge rate or voltage in the interval $50-150 \mathrm{~ms}$ minus the baseline in the interval $-50-0 \mathrm{~ms}$ relative to stimulus onset.

Error signal analysis. We identified errorrelated neurons and LFPs by comparing firing rates and voltage on trials in which the animal made a correct saccade to the target with trials in which the animal made an incorrect saccade to a distractor. Errors in which the monkey prematurely broke fixation, failed to maintain fixation on the target, or initiated a saccade to an empty location were rare and are not considered further. LFPs were baseline corrected $-50-0 \mathrm{~ms}$ relative to saccade onset to eliminate differences in presaccadic modulation. A neuron or LFP was classified as error related if modulation was significantly greater when the monkey made an erroneous saccade to a distractor as when the monkey made a correct saccade to the target in the interval 100-300 ms after the saccade ( $t$ test, $p<0.05$ ). The number of trials in which erroneous saccades were made to each location was matched across locations by excluding random trials. The number of trials in which correct saccades were made to each location was matched to the trial counts for error saccades by excluding random trials. Thus, the distributions of saccade directions were identical when comparing correct and error trials. Trials in which the animal failed to maintain fixation for $400 \mathrm{~ms}$ were excluded to eliminate the influence of nontask-related eye movements (e.g., unrewarded corrective saccades to the target). This analysis used only neurons and LFPs recorded during sessions in which the target was varied across blocks because monkeys made few errors when the target remained constant ( $\sim 93 \%$ correct). Most errors occurred on trials following changes in target identity, but we found no difference in postsaccadic activity on switch and nonswitch trials; therefore, we combined across all error trials regardless of the number of trials since the switch.

\section{Results}

\section{Absence of salience in SEF spiking activity during visual search}

We recorded 135 SEF neurons ( 92 from monkey F; 43 from monkey Z) that exhibited discharge rate modulation following stimulus presentation or around the time of saccade initiation. The neurons were verified to be in SEF based on histology and relation to microstimulation landmarks (Fig. 3). Our analysis of visual salience focuses on the subset of 95 visually responsive neurons that exhibited discharge rate modulation following stimulus pre-
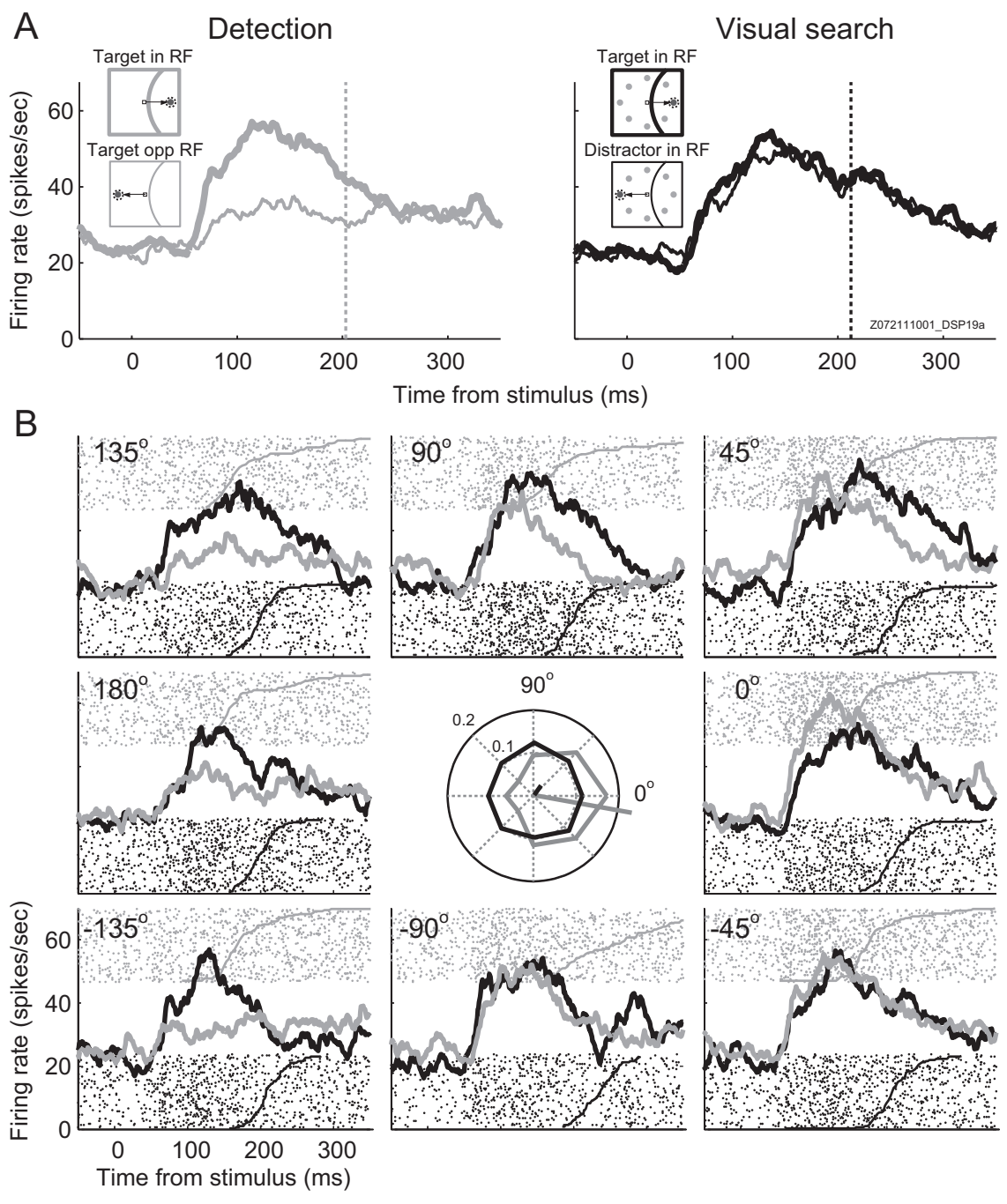

Figure 4. Representative visually responsive neuron during detection and search. $A$, Average spike density functions on trials uring indicates the directional bias, or strength of spatial tuning.

sentation. This included neurons recorded during sessions in which the target was constant and sessions in which the target changed in blocks. Of these neurons, 36 (38\%) were classified as pure visual neurons, which responded only following the stimulus onset, and 59 (62\%) were classified as visuomovement neurons, which responded both following stimulus onset and around the time of saccade. The mean SEF neuron visual latency $( \pm \mathrm{SE})$ was $71 \pm 2.4 \mathrm{~ms}$, which approximately corresponds to previous reports (Pouget et al., 2005).

Figure 4 shows the discharge rate of a representative visually responsive neuron during the detection and visual search tasks. We quantified the spatial selectivity of the neuron by computing a normalized vector sum of the neuron's response to the target at each polar angle. The angle of the resultant vector quantifies the direction of the center of a neuron's RF in polar angle, and the length quantifies the degree of selectivity. A neuron with a response field restricted to one target location would give a vector length of 1 , and a neuron with no response field and equal responsiveness to stimuli in all directions would give a vector length 
Table 1. Visually responsive neurons and LFPs classified as visually selective during single-target tasks and visual search

\begin{tabular}{|c|c|c|c|c|c|c|}
\hline \multirow[b]{2}{*}{ Monkeys } & \multicolumn{3}{|c|}{ Neurons } & \multicolumn{3}{|l|}{ LFPS } \\
\hline & Total & Select single target & Select search target & Total & Select single target & Select search target \\
\hline $\mathrm{F}$ & 69 & $44(63.8)$ & $1(1.4)$ & 145 & $51(35.2)$ & $13(9.0)$ \\
\hline Z & 26 & $14(53.8)$ & $1(3.8)$ & 40 & $11(27.5)$ & $2(5.0)$ \\
\hline Total & 95 & $58(61.1)$ & $2(2.1)$ & 185 & $62(33.5)$ & $15(8.1)$ \\
\hline
\end{tabular}

Selectivity was assessed by computing a directional bias using vector summation of the normalized response of the neuron or LFP when the target was presented at each of eight polar angles. A neuron or LFP was considered selective during a given task if the resultant vector was statistically significant according to a permutation test (1000 simulations, $p<0.05$ ). Values are given as number (\%) of visually responsive neurons and LFPs that selected targets.

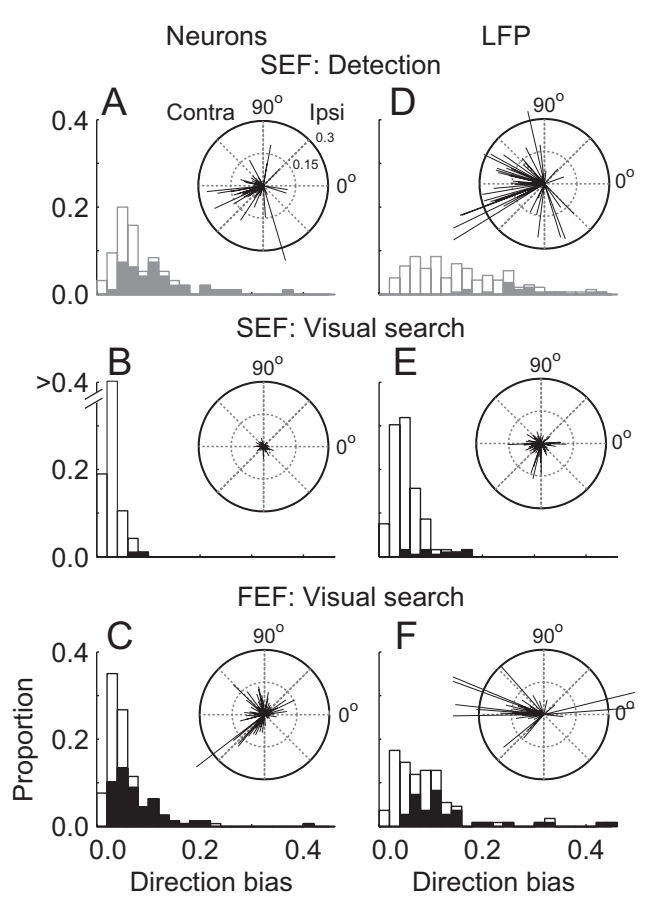

Figure 5. $\quad A-F$, Distribution of directional biases for visually responsive SEF and FEF neurons and LFPs. Filled histograms indicate neurons and LFP sites that were individually significant $(p<0.01)$. Insets illustrate the distribution of preferred locations (vector angle) and directional bias (vector length) for the population of neurons and LFP $\left(180^{\circ}\right.$, contralateral; $0^{\circ}$, ipsilateral).

near 0 . During detection, the visual response of the neuron was significantly spatially selective with the RF center at $-4.6^{\circ}$ (bootstrap, 1000 samples, $p<0.001)$. During visual search, however, this neuron exhibited no spatial selectivity in the RT interval ( $p=$ 0.31 ). In other words, this neuron has a clear RF, but does not discriminate whether it contained a salient singleton or a distractor.

Across the population of visually responsive neurons, we identified many neurons with spatially localized RFs as evidenced by significant spatial selectivity during the single-target tasks (Table 1; Fig. 5A). The RF centers tended to be located in the contralateral hemifield during both the detection (circular mean angle $=-160^{\circ}$; V-test, $\left.u=4.89, p<0.001\right)$ and memory-guided saccade task (circular mean angle $=-162^{\circ} ; u=4.66, p<0.001$ ). These observations are consistent with previous reports (Schlag and Schlag-Rey, 1987; Schall, 1991a; Russo and Bruce, 2000).

Although we observed many SEF neurons with well localized RFs, we found that vanishingly few exhibited significant target selectivity during visual search (Table 1 ). Figure $5 B$ summarizes the measure of vector tuning during search and detection. The mean directional bias during visual search $(0.02 \pm 0.002)$ was significantly lower than that measured during both detection $(0.11 \pm 0.01$; Wilcoxon rank sum test, $p<0.001)$ and memoryguided saccade tasks $(0.10 \pm 0.01 ; p<0.001)$, indicating that no spatial selectivity could be identified during search. No contralateral bias was present during search $(u=0.77, p=0.22)$. Thus, SEF neurons with clear RFs during single-target tasks failed to discriminate the target during visual search.

It is unclear from the preceding analysis whether the reduced selectivity reflects a true absence of salience or whether the reduced directional bias merely reflects reduced salience when additional stimuli are in the visual field. Therefore, we also analyzed single-unit activity recorded from FEF, an area known to encode salience (Thompson and Bichot, 2005). The FEF data were recorded from monkey $\mathrm{F}$ and two additional monkeys to compare directly the spatial selectivity during visual search across areas. The data from monkey F were previously published (Sato et al., 2001). The FEF dataset was comprised of 157 neurons (101 from monkey F; 32 from monkey Q; 24 from monkey S) with significant visual responses. The mean visual latency of the FEF neurons was $68 \pm 1.4 \mathrm{~ms}$, which is consistent with previous reports (Thompson et al., 1996; Schmolesky et al., 1998). Results were qualitatively similar across monkeys, so we combined data to increase statistical power.

In contrast to SEF, many FEF neurons (77/157, 49\%) exhibited significant target selectivity during search when measured in the same way (Fig. 5C). Spatial selectivity in FEF was significantly biased to the contralateral hemifield during search (circular mean angle $=157^{\circ}$; V-test, $u=3.95, p<0.001$ ) consistent with previous studies (Schall et al., 1995). The mean strength of directional bias in FEF $(0.04 \pm 0.007)$ was significantly greater than SEF neurons recorded during visual search (Wilcoxon rank-sum test, $p<0.001)$. This value is lower than previously reported values using single target tasks (Schall, 1991b) because the visual response to distractors decreases the length of the vector sum. Thus, our results reflect genuine differences in the role of these areas in representing visual salience.

To facilitate comparisons across areas and studies, we also quantified the magnitude of selectivity using a "neuron-antineuron" approach (Fig. 6). The magnitude of selectivity was determined as the area under the ROC curve when the target or distractors were inside a neuron's RF. During visual search, the neuron's discharge rate was approximately equal regardless of whether the target was inside or opposite the neuron's RF resulting in ROC values near 0.5 throughout the trial (Fig. 6A). Figure $6 B$ compares the mean magnitude of selectivity for SEF and FEF neurons that exhibited spatial selectivity when the target was presented alone during detection or memory-guided saccades. The mean magnitude of selectivity $( \pm \mathrm{SE})$ for SEF neurons is only slightly, but significantly, $>0.5(0.51 \pm 0.003 ; p<0.01)$. Thus, visually responsive SEF neurons are highly unreliable predictors of target location. In contrast, the mean magnitude of selectivity of FEF neurons is markedly and significantly $>0.5(0.58 \pm 0.003 ; p<0.001$; Wilcoxon signed-rank test $)$ and also significantly greater than the SEF neuron population $(p<0.001$, Wilcoxon rank-sum test). Thus, neurons in SEF, 

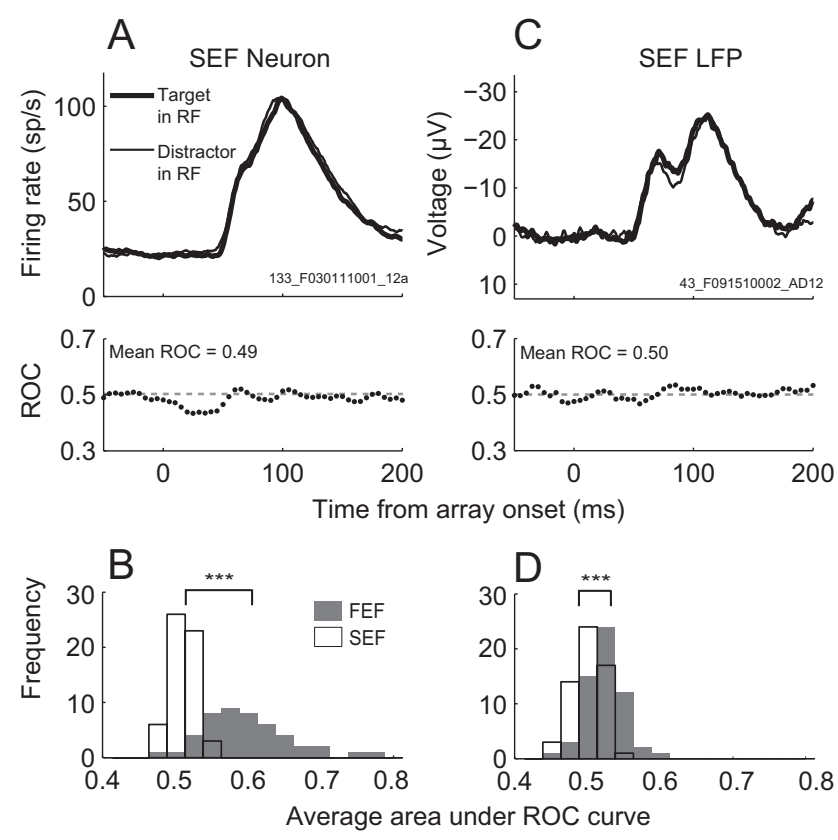

Figure 6. Neuron-antineuron test for target selectivity. $A, C$, Response of a representativeneuron $(A)$ and LFP site ( () during the visual search task in which a target (thick line) or distractor (thin line) appeared in the preferred location. Middle, The mean area under the ROC curve in a running $10 \mathrm{~ms}$ window. $\boldsymbol{B}, \boldsymbol{D}$, Distribution of average area under the $\mathrm{ROC}$ curve in the window $50 \mathrm{~ms}$ after array onset until $50 \mathrm{~ms}$ before mean saccade response time for SEF and FEF neurons $(\boldsymbol{B})$ and LFP $(\boldsymbol{D})$. Asterisks indicate significant difference between areas $\left({ }^{* * *} p<0.001\right.$, Wilcoxon rank-sum test).

unlike those in FEF, SC, LIP, and 7a, do not reliably discriminate the target from distractors.

\section{Absence of salience in SEF LFP during visual search}

LFP recorded in FEF exhibit differential polarization that discriminates the location of salient targets (Monosov et al., 2008; Cohen et al., 2009), but little is known about the spatial tuning or stimulus selectivity of SEF LFPs (but see Emeric et al., 2010). We have demonstrated that the spiking activity of SEF neurons does not encode a representation of visual search salience, but all single-unit recording studies are based on a limited sample of individual neurons within a given region of cortex. Therefore, it is possible that we did not encounter neurons in SEF that do represent search salience. To mitigate this concern, we also analyzed LFPs because they reflect the summed synaptic activity of thousands of neurons in the region of cortex surrounding the electrode tip (Mitzdorf, 1985; Katzner et al., 2009) and thus provide a more complete sampling of a region. In addition, LFPs reflect subthreshold fluctuations in membrane potential that may not have produced a spike (Poulet and Petersen, 2008; Okun et al., 2010) and may reflect both intrinsic processing and inputs from distant cortical areas (Logothetis and Wandell, 2004). Therefore, the LFPs in SEF may select the target despite an absence of spiking selectivity.

We recorded LFPs from 216 sites in SEF that exhibited taskrelated polarization ( 161 from monkey F; 55 from monkey Z), of which 185 sites exhibited significantly visually evoked polarization (Table 1). Of the 185 visually responsive LFP sites that formed the dataset for our analyses, $23(11 \%)$ were classified as pure visual LFPs, which showed significant modulation following only the stimulus onset, and $162(75 \%)$ were classified as visuomovement LFPs, which showed significant modulation following both stimulus onset and around the time of saccade initiation.
The greater percentage of visuomovement LFPs relative to neurons likely reflects summed activity across both visual and saccade-related neurons, which is consistent with the lack of evidence for modular or laminar differences in SEF neuron types. The visual latency of the SEF LFP was $54 \pm 0.7 \mathrm{~ms}$, which is significantly earlier than the latency of SEF neuron spike rate modulation ( $p<0.001$, Wilcoxon rank-sum test). This value is earlier than previous reports (Emeric et al., 2010), which were based on limited numbers of trials. All of our sessions included $>1000$ trials; therefore, we believe our latency estimate is more accurate.

Figure 7 shows the average response of a representative LFP site recorded during the detection and visual search tasks. During detection, the visually elicited polarization of the LFP varies significantly with target location with an RF center at $-142^{\circ}$ (bootstrap, 1000 samples, $p<0.001)$. During visual search, however, the LFPs recorded at the same site did not distinguish the target from distractors $(p=0.08)$.

We quantified the RF location and spatial selectivity of each LFP site using vector summation of the modulation at each target location as described above. Figure $5 D$ illustrates the preferred locations and directional bias for the 185 visually responsive LFP sites. Across the population of visually responsive LFP sites, many exhibited significant spatial selectivity when a single saccade target was presented (Table 1). The reduced percentage of visually responsive LFP relative to neurons likely reflects summed activity across neurons with different preferred locations. There is a clear bias to the contralateral hemifield during detection (circular mean angle $=-167^{\circ} ; \mathrm{V}$-test, $u=5.2, p<0.001$ ) and memoryguided saccades (circular mean angle $=-176^{\circ} ; u=6.8, p<$ 0.001 ), which has been previously reported using only two targets on the horizontal meridian (Emeric et al., 2010).

Although many LFP sites had spatially selective modulation, very few LFP sites exhibited significant target selectivity during visual search (Table 1). Figure 5, $D$ and $E$, summarizes the strength of directional bias during search and detection. The mean strength of directional bias during search $(0.05 \pm 0.005)$ was significantly reduced relative to both detection $(0.21 \pm 0.02)$ and memory-guided saccade $(0.22 \pm 0.01)$ tasks (Wilcoxon rank-sum test, $p<0.001)$. There was no significant difference in the strength of spatial selectivity between detection and memoryguided saccade tasks ( $p=0.48$ ). Thus, many LFP sites with spatially selective modulation during single target tasks fail to select the target during search.

We compared the strength of target selection in SEF LFPs to LFPs recorded from the FEF of two additional monkeys that performed the color visual search task. The dataset was comprised of 109 LFP with significant visual modulation following stimulus onset (73 from Monkey Q; 36 from Monkey S). Of these, 42 of 109 (38\%) exhibited significant target selectivity during search. The mean visual latency of the FEF LFPs was $53.0 \pm 2.0 \mathrm{~ms}$, which is consistent with previous reports (Monosov et al., 2008; Cohen et al., 2009). Figure $5 F$ illustrates the distribution of FEF LFPs preferred directions and directional biases. Directional selectivity was significantly biased to the contralateral hemified during search (circular mean angle $=174^{\circ} ;$ V-test, $u=6.03, p<0.001$ ), consistent with previous reports (Monosov et al., 2008). During search, the strength of directional bias in FEF $(0.35 \pm 0.21)$ was significantly greater than the directional bias in SEF (Wilcoxon rank-sum test, $p<0.001)$. Thus, target selectivity is evident in FEF, but not SEF, LFPs.

We confirmed the absence of selectivity in SEF LFPs by computing the area under the ROC curve over the course of the trial 

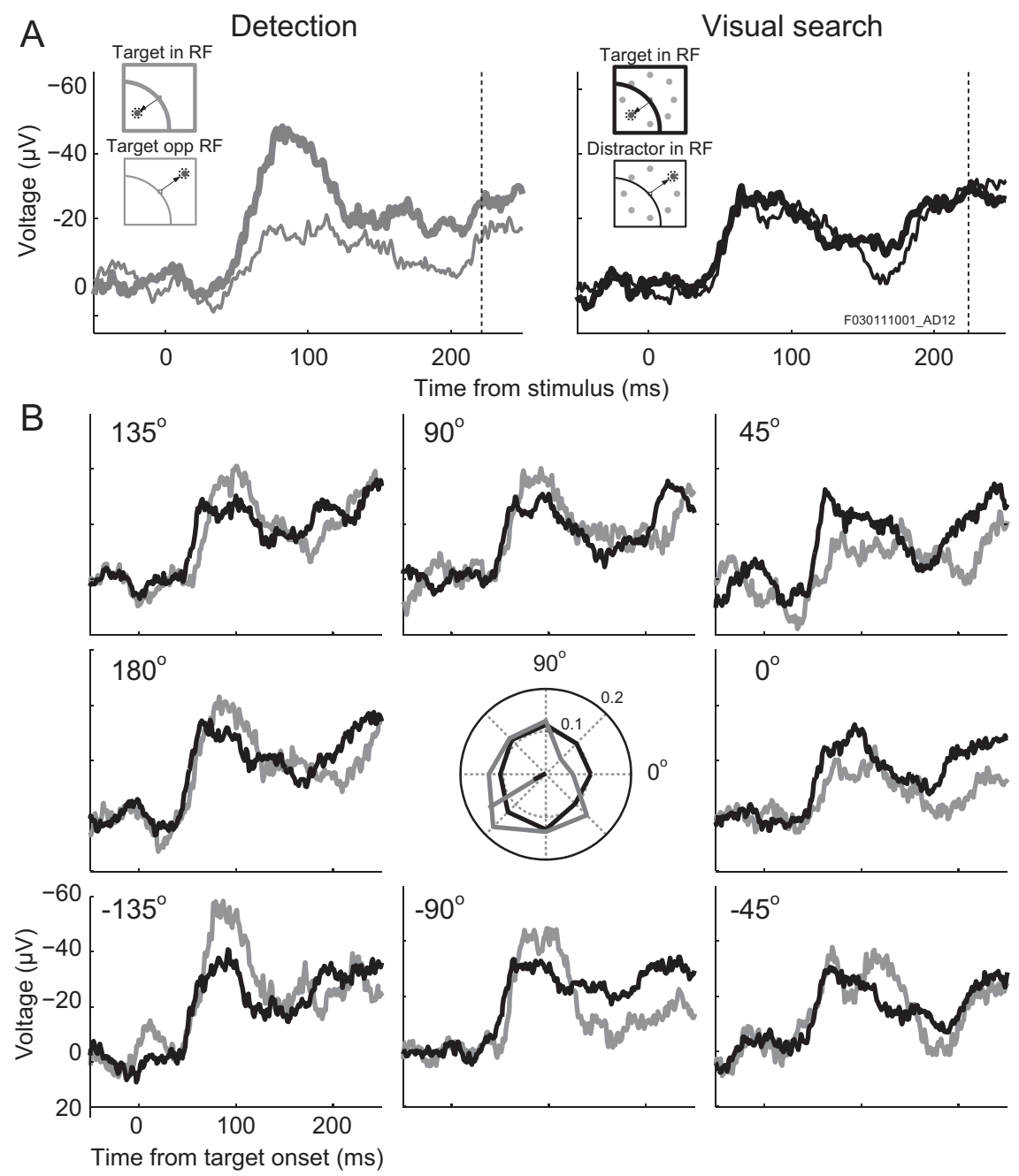

Figure 7. Representative visually responsive LFP site during detection and search. Conventions are as in Figure 4. greater than the SEF LFP population $(p<$ $0.001)$. Thus, we found no evidence that SEF represents salience during search even when taking into account population level signals that include subthreshold synaptic activity.

\section{Comparison of visual responses in SEF and FEF}

We characterized two properties of SEF neurons and LFPs to determine whether they distinguish SEF from other visuomotor areas that encode salience. First, we compared the tuning widths of neurons and LFPs. Following Bruce and Goldberg (1985), we used the SD of a Gaussian function fitted to the mean discharge rate/voltage of each neuron/LFP as a function of target position during the memory-guided saccade task as an indicator of tuning width. The mean tuning width for SEF neurons $\left(56^{\circ} \pm 4.0^{\circ}\right.$, degrees of polar angle $)$ was significantly narrower than the mean tuning width for SEF LFPs $\left(82^{\circ} \pm 3.8^{\circ}\right.$; Wilcoxon rank-sum test; $p<0.001$ ) (Fig. 8). Similarly, the mean tuning width of FEF neurons $\left(51^{\circ}\right.$ $\pm 3.1^{\circ}$ ) was significantly narrower than the mean tuning width for FEF LFPs $\left(65^{\circ} \pm\right.$ $3.3^{\circ}$ ). This is consistent with the hypothesis that LFPs in both areas are integrating across neurons with scattered RFs (Monosov et al., 2008). The slight increase in mean tuning width in SEF relative to FEF was significant for LFPs $(p<0.01)$, but not neurons ( $p=$ $0.38)$. When converted to visual field angles using the law of cosines, the estimated RF width at $10^{\circ}$ eccentricity was $9^{\circ} \pm 0.6^{\circ}$ for SEF neurons and $13^{\circ} \pm 0.5^{\circ}$ for SEF LFPs.
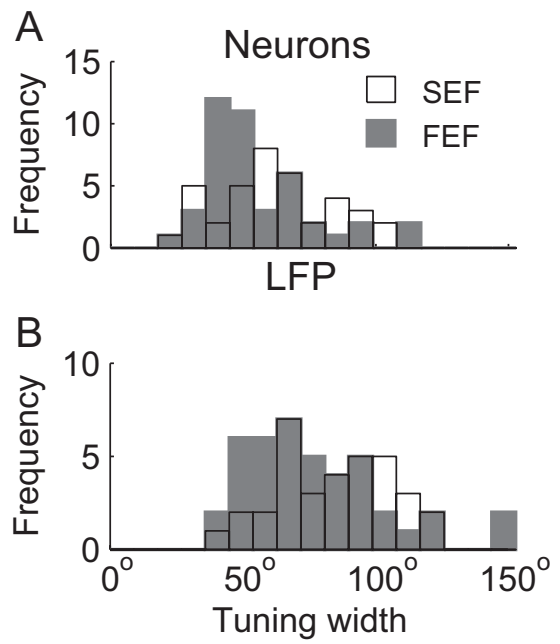

Figure 8. $\quad A, B$, The distribution of receptive field widths for SEF (open histogram) and FEF (solid histogram) across the population of neurons across the population of neurons $(\boldsymbol{A})$ and LFP (B) during the memory-guided saccade task.

(Fig. 6C,D). The mean magnitude of selectivity for SEF LFPs was not significantly different from $0.5(0.48 \pm 0.014 ; p=0.85)$. In contrast, the mean magnitude of selectivity for FEF LFP was significantly $>0.5(0.53 \pm 0.004 ; p=0.85)$ and also significantly
The estimated RF width of FEF neurons was $8^{\circ} \pm 0.4^{\circ}$, and that of FEF LFPs was $11^{\circ} \pm 0.5^{\circ}$. Note that these estimates are based on only a single eccentricity $\left(10^{\circ}\right.$ visual angle $)$ and RF width is known to vary with eccentricity in both FEF and SEF (Bruce and Goldberg, 1985; Russo and Bruce, 2000). However, at the eccentricity tested, the tuning widths of SEF neurons and LFPs are approximately comparable to those observed in FEFs (Schall, 1991b; Russo and Bruce, 2000).

Second, we determined whether adding distractor stimuli to the visual field inhibited SEF visual responses. FEF, LIP, and SC neurons are suppressed by the addition of stimuli outside their RF (Schall et al., 1995b; Basso and Wurtz, 1998; McPeek and Keller, 2002; Falkner et al., 2010), which suggests some form of lateral inhibition that is thought to be critical for generating a salience representation (Tsotsos et al., 1995; Itti and Koch, 2001). The mean visual response of SEF neurons was significantly reduced during search relative to detection (Fig. 9A, B; mean difference: $2.9 \pm 0.7$ spikes/second; $p<0.001$, Wilcoxon signed-rank test). Similarly, the mean visual polarization of SEF LFPs was significantly reduced during search relative to detection (Fig. 9C,D;2.1 $\pm 0.4 \mu \mathrm{V} ; p<0.001$ ). Thus, both FEF and SEF neurons and LFPs show evidence of lateral inhibition.

\section{Absence of cognitive control in SEF during priming of pop-out}

Medial frontal areas, including SEF, are thought to be involved in overcoming habitual actions in response to changing environ- 
mental demands (Schlag-Rey et al., 1997; Rushworth et al., 2002; Nakamura et al., 2005; Isoda and Hikosaka, 2007; Schall and Boucher, 2007; Sumner et al., 2007). We used a priming of popout manipulation in which the target and distractor color were swapped randomly after several trials (Fig. 10A) to test whether SEF contributed to overcoming the primed tendency to look to the previous target color on trials in which target identity switched. Following target switches, both humans and monkeys are slower and more error prone, but performance improves over the next several trials (Maljkovic and Nakayama, 1994; McPeek and Keller, 2001; Bichot and Schall, 2002). FEF neurons show robust modulation with changes in performance with priming of pop-out (Bichot and Schall, 2002), but nothing is known about SEF neurons. Therefore, we also tested whether SEF contributed to improvements in performance in the trials following the switch.

Both monkeys exhibited clear behavioral evidence of priming (Fig. $10 B, C$ ). The mean saccade response time was significantly longer on switch trials relative to nonswitch trials (Wilcoxon signed-rank test; monkey F, 16 ms, $p<0.001$; monkey Z, $22 \mathrm{~ms}$, $p<0.001$ ), and percentage correct was significantly lower (monkey F, 27\%, $p<0.001$; monkey Z, 28\%, $p<0.001$ ). We tested for significant improvements in performance following the target switch by fitting a least-squares regression line to saccade response time and percentage correct as a function of the first five trials since the target switch. Response times declined at an average rate of 4.4 $\mathrm{ms} /$ trial following the switch $(p<0.001)$, and percentage correct increased an average of $6 \%$ per trial $(p<0.001)$, though the largest improvements in performance followed the first trial since the switch. Thus, the monkeys exhibited clear and robust evidence of priming.

We recorded 91 neurons (29 from monkey F; 62 from monkey Z) that exhibited significant task-related modulation around the time of saccade or following stimulus presentation during priming of pop-out. These analyses included all task-related neurons, not only visually responsive neurons. If SEF is involved in overcoming priming, then we would expect changes in discharge rate on switch trials relative to nonswitch trials before the saccade (Isoda and Hikosaka, 2007). Figure $11 \mathrm{~A}$ illustrates the activity of a representative neuron recorded during priming of pop-out. The neuron's response was invariant whether or not the target color switched across trials $(p>0.05$, Wilcoxon rank-sum test). Across the population of neurons, the difference in discharge rate across switch and nonswitch trials was indistinguishable (Fig. $12 B ; p=$ $0.26)$. This was true regardless of whether the target (Fig. $11 C ; p=0.63$ ) or distractors (Fig. $11 D ; p=0.39$ ) fell within the RF of the cell. The same pattern was evident in SEF LFPs (all $p>0.05$ ). Clearly, SEF neurons do not exhibit appropriate modulation to have controlled changes in performance following target switches.

Behavioral performance improves in the trials following a target switch. If SEF is involved in performance improvements, then
A
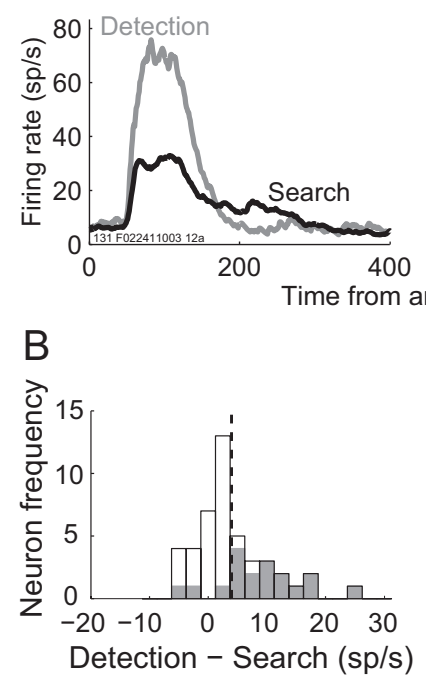

C

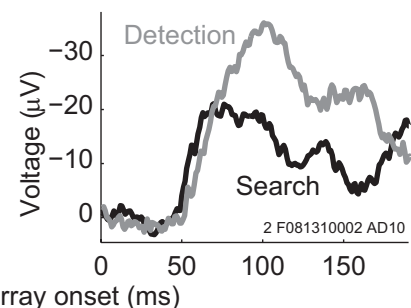

$\mathrm{D}$

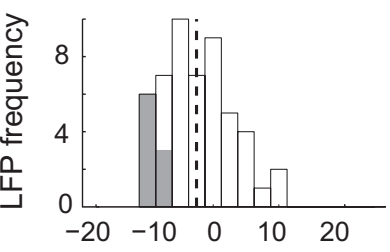

Detection - Search $(\mu \mathrm{V})$
Figure 9. $\quad \boldsymbol{A}, \boldsymbol{C}$, Representative SEF neuron (A) and LFP $(\boldsymbol{C})$ during detection (gray) and visual search tasks (black) when the target fell inside the RF. $\boldsymbol{B}, \boldsymbol{D}$, Distribution of differences between the mean discharge rate 50 to $150 \mathrm{~ms}$ after array onset for the population of visually responsive neurons $(\boldsymbol{B})$ and LFPs $(\boldsymbol{D})$ during detection and visual search. Shaded bars indicate neurons that attained individual statistical significant (Wilcoxon signed-rank test, $p<0.05$ ). Dashed vertical line indicates population mean.
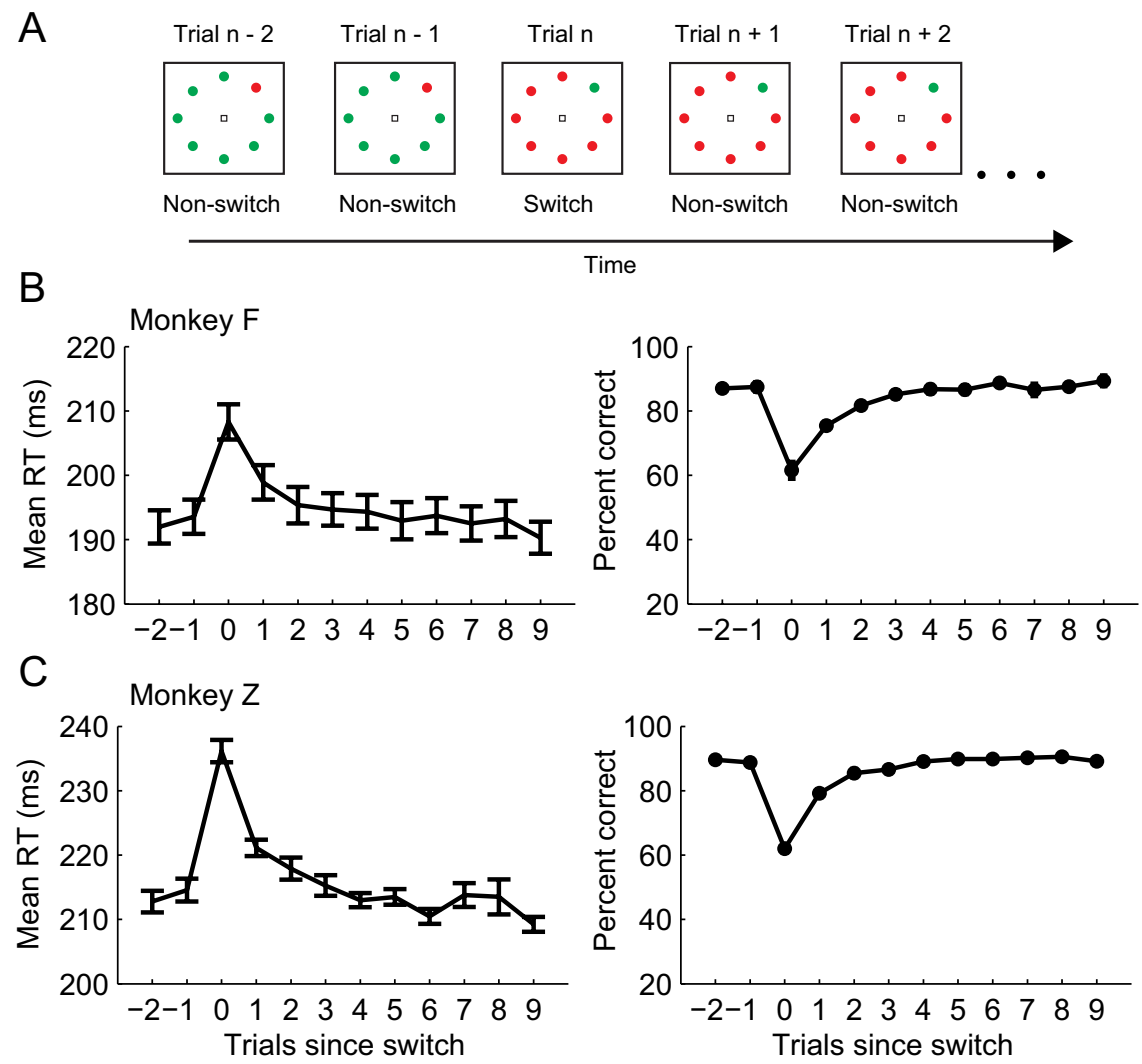

Figure 10. Priming of pop-out task and behavior. $\boldsymbol{A}$, The color of the target and distractors switched randomly every $8-16$ trials (uniform distribution). $\boldsymbol{B}, \boldsymbol{C}$, mean response time (left) and percentage correct (right) as a function of the number of trials since the switch in target identity in Monkey $\mathrm{F}(\boldsymbol{B})$ and Monkey $Z(\boldsymbol{C})$.

we would expect systematic changes in the discharge rate of SEF neurons throughout the trial. Figure 12 illustrates the discharge rate of the same representative neuron as a function of the number of trials since the target switch. In contrast to FEF neurons 
A

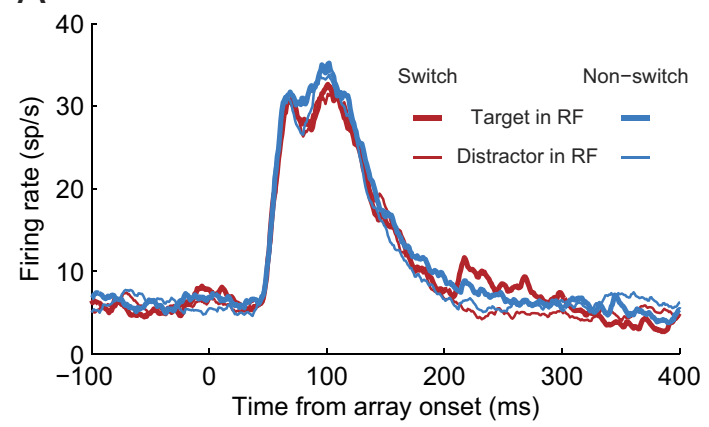

B

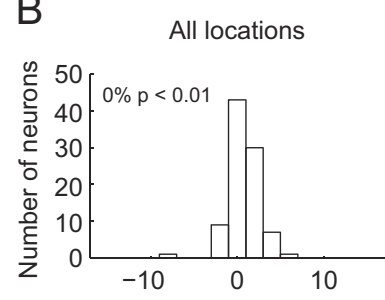

C Target in RF

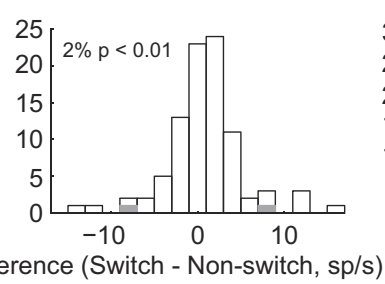

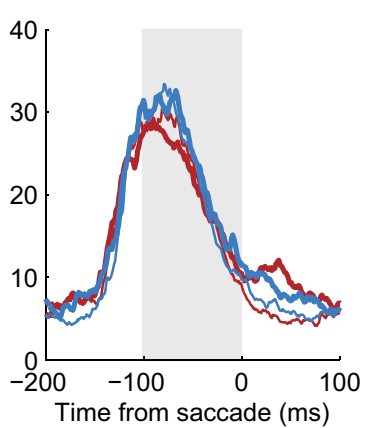

$\mathrm{D}$

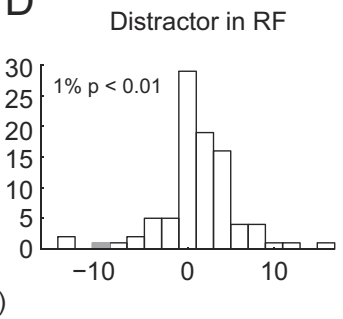

Figure 11. A, Mean discharge rate of a representative neuron recorded during the priming of pop-out task when the target. At no point does the response of the neuron depend on whether the target identity switched or remained constant from the previous trial. $\boldsymbol{B}-\boldsymbol{D}$, histograms illustrate the population difference in discharge rate between switch and nonswitch trials $-100-0 \mathrm{~ms}$ relative to saccade onset when any stimulus $(\boldsymbol{B})$, the target $(\boldsymbol{C})$, or distractors $(\boldsymbol{D})$ were in the neuron's RF. Shaded bars indicate neurons that attained individual significance (Wilcoxon rank-sum test, $p<0.01$ ).

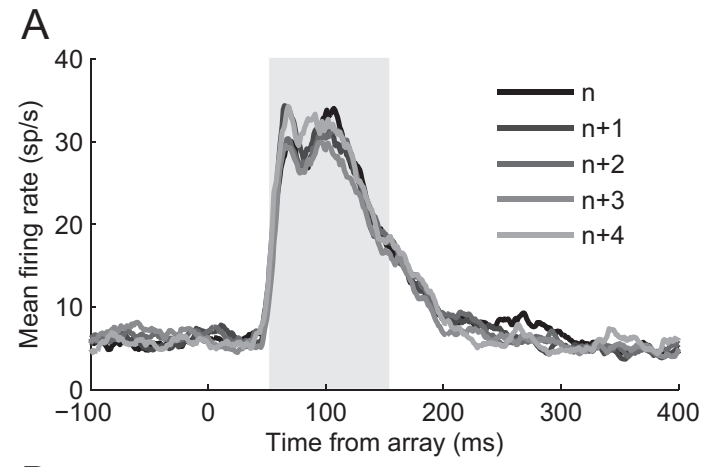

B
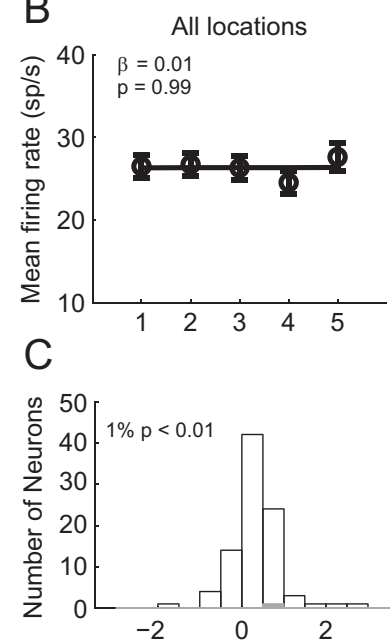
Trials since switch

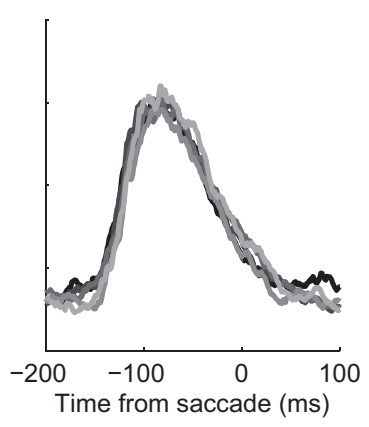

Target opposite RF $\beta=-0.11$ $p=0.86$

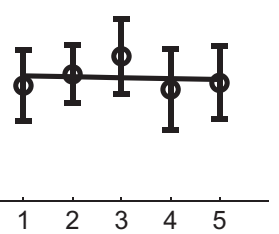

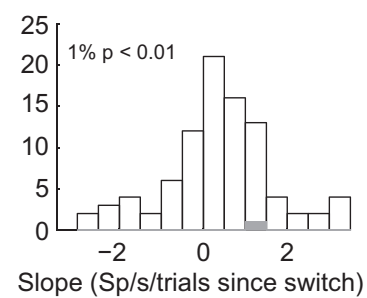

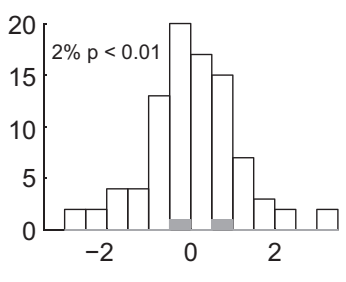

Figure 12. $A$, Themean dischargerate of the same representativeneuron shown in Figure 11 with dischargerate divided by thenumber of trials sincethetargetswitch $(n) \cdot \boldsymbol{B}$, themean dischargerate of theneuron in theinterval $50-150$ msfollowing array onsetandleast-squares regression line. C, the distribution of slopes of least-squares regression lines fitted to discharge rate as a function of trials since target switch for the population of neurons when any stimulus (left), the target (middle), or distractor (right) were within the RF of the cell.

(Bichot and Schall, 2002), there is no monotonic change in discharge rate as performance improves in the trials following the target switch. We fit a leastsquares regression line to the discharge rate as a function of the first five trials since the target switch to test for covariation of discharge rate with improvements in performance. The slope of the regression line was not significant for this neuron regardless of whether the target or distractors were inside the neuron's RF (Fig. 12B). Across the population of neurons, the distribution of slopes was not significantly different from zero regardless of the stimulus in the neuron's RF (all $p>0.05$ ), and only chance percentages of neurons attained individual significance (Fig. 12C). The results were qualitatively similar if discharge rate was directly correlated with saccade response time or percentage correct as a function of trials since the switch. The same pattern was evident in SEF LFPs (all $p>0.05$ ). Thus, SEF does not control performance adjustments observed during priming of pop-out.

\section{Performance monitoring in SEF during visual search}

We found that SEF neurons and LFPs do not signal the location of salient saccade targets and do not modulate with changes in behavior during priming of pop-out. Does SEF contribute at all to search performance? SEF neurons and LFPs signal the occurrence of errors during saccade countermanding (Stuphorn et al., 2000; Emeric et al., 2010), which is thought to produce error-related potentials observed extracranially (Godlove et al., 2011). However, this observation has never been replicated in another task. Therefore, we asked whether SEF neurons or LFPs signal the occurrence of an error when the monkeys incorrectly shifted gaze to a distractor location during visual search.

We tested for error-related responses in the 91 neurons recorded during the priming of pop-out manipulation, which provided sufficient numbers of error trials. Figure $13 \mathrm{~A}$ shows the response of a representative error-related SEF neuron. Following a brief perisaccadic suppression, activity remained at baseline for correct trials to the target, but exhibited a brisk discharge $\sim 100-200 \mathrm{~ms}$ after erroneous saccades to a distractor. Across the population of neurons, 24 of 91 (26\%) exhibited significant error-related modulations. This is only slightly higher than previous estimates during saccade countermanding (Stuphorn et al., 2000). Figure 13B shows the response of a representative 

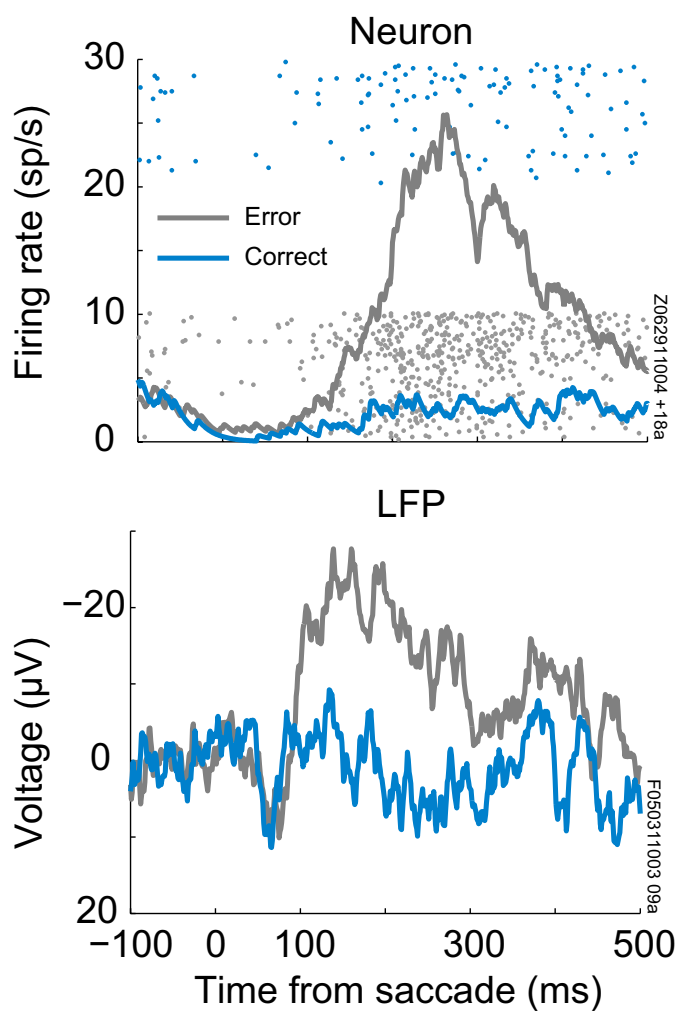

Figure 13. Representative error-related neuron during detection and search. Top, Average spike density function (lines) and raster (dots) for trials in which a saccade was correctly made to the target (blue) or erroneously made to a distractor (gray). Bottom, Average voltage for correct and error trials. Conventions are as in top.

LFP site with error-related modulation. Following the saccade, a brief positive-going polarization was followed by a significant negative polarization following erroneous but not correct saccades. Across the population of LFP sites, 17 of 107 (16\%) exhibited significant error-related modulation. This is slightly lower than previous estimates (Emeric et al., 2010). Importantly, these effects cannot be due to the shift of gaze because we matched the distribution of saccade directions across all analyzed correct and error trials. These effects cannot be due to second saccades (corrective saccades to the target) because trials in which the eyes moved $<400 \mathrm{~ms}$ after the initial saccade were excluded. Thus, we conclude that SEF neurons are signaling the occurrence of an error during visual search.

\section{Discussion}

SEF is embedded anatomically within a network of structures that represent visual salience (physical conspicuousness and behavioral relevance). We found that SEF neurons and LFPs do not represent visual salience. We also found that SEF is not involved in overcoming priming during pop-out, but did signal the occurrence of search saccade errors.

\footnotetext{
Absence of salience in SEF

Anatomical connections with cortical and subcortical areas known to encode salience suggested that SEF would represent another node in this network (Fig. 1). Previous single-unit recording studies in SEF also suggest that it may represent salience. When presented with foveal cues, some SEF neurons fire selectively before saccades to targets (Chen and Wise, 1995a,b, 1996; Olson et al., 2000). Other populations of SEF neurons signify the
}

target of an upcoming saccade on the basis of reward contingencies (Coe et al., 2002; Seo and Lee, 2009; So and Stuphorn, 2010, 2012) or by virtue of its position in a sequence of saccades (Lu et al., 2002; Berdyyeva and Olson, 2009, 2010). Human imaging studies suggest that SEF may be active during deployment of covert attention (Kastner et al., 1999). These factors can be viewed as "top-down" salience, but we showed that SEF neurons and LFPs do not discriminate the target from distractors during visual search. This is consistent with the relatively limited deficits in target selection observed following lesions of contralateral SEF relative to FEF lesions (Schiller and Chou, 1998, 2000) and the absence of fMRI signals in monkeys presented with pop-out arrays (Wardak et al., 2010).

Our finding that salience is absent in SEF parallels a recent report showing that saccade-related SEF neurons do not directly control saccade initiation (Stuphorn et al., 2010). Many FEF, SC, and SEF neurons show elevated discharge rates before saccades of particular directions (Schlag and Schlag-Rey, 1987), which has been suggested to indicate a similar role in saccade generation (Schall, 1991b; Russo and Bruce, 2000). FEF and SC neurons modulate early enough to control saccade initiation (Hanes et al., 1998; Paré and Hanes, 2003), but SEF neurons modulated too late to control saccade initiation (Stuphorn et al., 2010). Similarly, we found that although both SEF and FEF neurons have selective visual responses, SEF neurons do not encode salience. SEF may be less important for ongoing decisions about where to move the eyes (see also Yang et al., 2010), but may play a larger role in monitoring the outcome of prior decisions (Schall and Boucher, 2007).

\section{Does salience require ventral stream innervation?}

The lack of target selectivity and priming effects in SEF neurons is most likely due to an absence of necessary visual afferents (Fig. 1). FEF, LIP, and SC all receive topographically organized input from visual areas V4, temporal-occipital (TEO), temporal (TE), middle temporal (MT), and medial superior temporal (MST) representing features of objects on which search can be performed such as color, shape, texture, motion, and depth (Blatt et al., 1990; Lui et al., 1995; Schall et al., 1995a; Bullier et al., 1996). In contrast, SEF receives cortical visual input only from areas LIP, 7a, FEF, MST, and the superior temporal polysensory area (Huerta and Kaas, 1990; Schall et al., 1995a). Thus, the absence of a salience representation in SEF can be understood from the lack of visual afferents originating in areas representing stimulus features. Our result is interesting to consider in relation to a recent study that found that FEF neurons projecting to MT are targeted by SEF neurons, but not FEF neurons projecting to V4 (Ninomiya et al., 2012).

We ruled out several alternative explanations for the absence of visual salience in SEF. It could be explained by an absence of topographic visual inputs. However, many SEF neurons and LFP sites exhibited well localized RFs. Furthermore, SEF neuron and LFP tuning widths were, on average, only slightly broader than FEF (Bruce and Goldberg, 1985; Schall et al., 1995b; Schall et al., 2004; Monosov et al., 2008). Thus, the absence of topographic visual inputs cannot explain the absence of salience.

Alternatively, the absence of salience could be explained by an absence of lateral inhibition. Several computational models propose that salience is shaped by suppression of distractor inputs (Tsotsos et al., 1995; Itti and Koch, 2001), and that lateral inhibition is observed throughout the visual system including FEF (Schall et al., 1995b), SC (McPeek and Keller, 2002), and LIP (Falkner et al., 2010). We found that the response of most SEF 
neurons and LFPs were significantly inhibited by the addition of distractor stimuli in the visual field. This could be due to lateral connections intrinsic to SEF or could reflect competitive interactions taking place in afferent areas. Regardless, an absence of lateral inhibition cannot explain the absence of salience in SEF.

The absence of a salience representation in SEF has implications for the functional connectivity between SEF and other areas in the salience network. Visually responsive neurons in the superficial layers of FEF encode a representation of salience (Thompson et al., 1996) and project to areas of extrastriate visual cortex (Huerta et al., 1987; Barone et al., 2000; Pouget et al., 2009; Anderson et al., 2011), which are thought to contribute to covert spatial attention (Moore and Armstrong, 2003; Cohen et al., 2009; Purcell et al., 2010). Given that collateralization of intracortical projections is so limited, the absence of a salience signal in SEF suggests that the neurons in LIP and FEF that encode salience do not project to SEF. Alternatively, the absence of salience in SEF could be due to active cancellation via local-circuit connections. However, the small proportion of neurons and LFP sites that exhibited significant salience signals indicates that these input signals must be suppressed very early in the network, which makes it of limited use for subsequent computations.

\section{Absence of priming effects in SEF neurons}

Dorsomedial frontal areas, including SEF, have been implicated in the control processes necessary to overcome a habitual action in response to changing context (Rushworth et al., 2002; Isoda and Hikosaka, 2007; Sumner et al., 2007) (for review, see Isoda and Hikosaka, 2011). The priming of pop-out task requires the animal to overcome the primed tendency to respond to an old target color. Our monkeys showed clear evidence of priming; target color switches lead to increased response times and error rates. However, we found no modulation in presaccadic discharge rates when the target color switched across our entire sample of SEF neurons or LFP. This suggests that SEF is not necessary to overcome priming of pop-out.

We do not believe that the absence of SEF modulation during priming of pop-out can be explained by an absence of control signals in SEF. Pre-SMA is strongly interconnected with SEF (Huerta and Kaas, 1990; Luppino et al., 1993), and neurons in this area are strongly modulated on trials in which a primed response must be suppressed (Isoda and Hikosaka, 2007). Humans with lesions of SEF show an absence of priming effects in oculomotor tasks (Sumner et al., 2007). Furthermore, SEF neurons fire vigorously during tasks that encourage mutually incompatible responses including anti-saccade (Schlag-Rey et al., 1997), countermanding (Stuphorn et al., 2000, 2010), and flanker tasks (Nakamura et al., 2005). Thus, the absence of priming effects during pop-out does not rule out a role for SEF as a source of control during tasks in which competing responses are actively suppressed.

Instead, the absence of modulation in SEF neurons can be explained if delays in early perceptual processes completely account for pop-out priming. Consistent with this account, priming effects cannot be eliminated by voluntary control or expectation (Maljkovic and Nakayama, 1994). Priming effects correlate with reductions in BOLD activity in extrastriate visual areas (Kristjánsson et al., 2007). Transcranial magnetic stimulation applied to visual area MT in humans disrupts motion priming (Campana et al., 2006). Finally, lesions of TEO and V4 in monkeys lead to an abolished priming effect (Walsh et al., 2000), but lesions of dorsolateral prefrontal cortex do not eliminate priming (Rossi et al., 2007). SEF does not receive input from these visual areas, and cognitive control is not necessary for perceptual priming; therefore, priming effects are not apparent in this area. Thus, our results add to converging evidence that priming of pop-out can be entirely accounted for by changes at the level of early feature representations (Wolfe et al., 2003; Lee et al., 2009). We speculate that other tasks (e.g., countermanding) elicited control responses in SEF because those tasks, unlike priming of pop-out, encouraged early preparation of saccade responses that required active suppression by SEF.

\section{Performance-monitoring signals in SEF during visual search}

We have ruled out two of the most plausible ways in which SEF could contribute to visual search performance, but what role, if any, does SEF play during visual search? SEF neurons and LFPs modulate following errors during saccade countermanding (Stuphorn et al., 2000; Emeric et al., 2010), which is one likely source of error-related potentials recorded extracranially (Godlove et al., 2011). We found that SEF neurons signaled visual search errors when monkeys incorrectly made saccades to a distractor. Modulation followed saccade initiation and therefore could not play a role in representing salience to guide current search behavior. Rather, these observations can be understood in the context of a performance-monitoring framework (Schall and Boucher, 2007). Although SEF does not appear to be actively engaged in modifying ongoing visual search performance, it may play a role in monitoring performance and relaying outcome information to other cortical areas for subsequent behavioral adjustments.

\section{References}

Andersen RA, Asanuma C, Essick G, Siegel RM (1990) Corticocortical connections of anatomically and physiologically defined subdivisions within the inferior parietal lobule. J Comp Neurol 296:65-113.

Anderson JC, Kennedy H, Martin KA (2011) Pathways of attention: synaptic relationships of frontal eye field to V4, lateral intraparietal cortex, and area 46 in macaque monkey. J Neurosci 31:10872-10881.

Arcizet F, Mirpour K, Bisley JW (2011) A pure salience response in posterior parietal cortex. Cereb Cortex 21:2498-2506.

Balan PF, Oristaglio J, Schneider DM, Gottlieb J (2008) Neuronal correlates of the set-size effect in monkey lateral intraparietal area. PLoS Biol 6:e158.

Barone P, Batardiere A, Knoblauch K, Kennedy H (2000) Laminar distribution of neurons in extrastriate areas projecting to visual areas V1 and V4 correlates with the hierarchical rank and indicates the operation of a distance rule. J Neurosci 20:3263-3281.

Basso MA, Wurtz RH (1998) Modulation of neuronal activity in superior colliculus by changes in target probability. J Neurosci 18:7519-7534.

Basso MA, Wurtz RH (2002) Neuronal activity in substantia nigra pars reticulata during target selection. J Neurosci 22:1883-1894.

Batschelet E (1981) Circular statistics in biology. New York: Academic.

Berdyyeva TK, Olson CR (2009) Monkey supplementary eye field neurons signal the ordinal position of both actions and objects. J Neurosci 29:591-599.

Berdyyeva TK, Olson CR (2010) Rank signals in four areas of macaque frontal cortex during selection of actions and objects in serial order. J Neurophysiol 104:141-159.

Bichot NP, Schall JD (1999) Saccade target selection in macaque during feature and conjunction visual search. Vis Neurosci 16:81-89.

Bichot NP, Schall JD (2002) Priming in macaque frontal cortex during popout visual search: feature-based facilitation and location-based inhibition of return. J Neurosci 22:4675-4685.

Bisley JW, Goldberg ME (2010) Attention, intention, and priority in the parietal lobe. Annu Rev Neurosci 33:1-21.

Blatt GJ, Andersen RA, Stoner GR (1990) Visual receptive field organization and cortico-cortical connections of the lateral intraparietal area (area LIP) in the macaque. J Comp Neurol 299:421-445.

Bruce CJ, Goldberg ME (1985) Primate frontal eye fields. I. Single neurons discharging before saccades. J Neurophysiol 53:603-635.

Bruce CJ, Goldberg ME, Bushnell MC, Stanton GB (1985) Primate frontal eye fields. II. Physiological and anatomical correlates of electrically evoked eye movements. J Neurophysiol 54:714-734. 
Bullier J, Schall JD, Morel A (1996) Functional streams in occipito-frontal connections in the monkey. Behav Brain Res 76:89-97.

Bundesen C, Habekost T, Kyllingsbaek S (2005) A neural theory of visual attention: bridging cognition and neurophysiology. Psychol Rev 112:291-328.

Campana G, Cowey A, Walsh V (2006) Visual area V5/MT remembers what but not where. Cereb Cortex 16:1766-1770.

Campos M, Breznen B, Andersen RA (2009) Separate representations of target and timing cue locations in the supplementary eye fields. J Neurophysiol 101:448-459.

Chen LL, Wise SP (1995a) Neuronal activity in the supplementary eye field during acquisition of conditional oculomotor associations. J Neurophysiol 73:1101-1121.

Chen LL, Wise SP (1995b) Supplementary eye field contrasted with the frontal eye field during acquisition of conditional oculomotor associations. J Neurophysiol 73:1122-1134.

Chen LL, Wise SP (1996) Evolution of directional preferences in the supplementary eye field during acquisition of conditional oculomotor associations. J Neurosci 16:3067-3081.

Coe B, Tomihara K, Matsuzawa M, Hikosaka O (2002) Visual and anticipatory bias in three cortical eye fields of the monkey during an adaptive decision-making task. J Neurosci 22:5081-5090.

Cohen JY, Heitz RP, Schall JD, Woodman GF (2009) On the origin of eventrelated potentials indexing covert attentional selection during visual search. J Neurophysiol 102:2375-2386.

Constantinidis C, Steinmetz MA (2001) Neuronal responses in area 7a to multiple-stimulus displays: I. Neurons encode the location of the salient stimulus. Cereb Cortex 11:581-591.

Emeric EE, Leslie M, Pouget P, Schall JD (2010) Performance monitoring local field potentials in the medial frontal cortex of primates: supplementary eye field. J Neurophysiol 104:1523-1537.

Falkner AL, Krishna BS, Goldberg ME (2010) Surround suppression sharpens the priority map in the lateral intraparietal area. J Neurosci 30:12787-12797.

Findlay JM, Walker R (1999) A model of saccade generation based on parallel processing and competitive inhibition. Behav Brain Sci 22:661-674.

Georgopoulos AP, Kettner RE, Schwartz AB (1988) Primate motor cortex and free arm movements to visual targets in three-dimensional space. II. Coding of the direction of movement by a neuronal population. J Neurosci 8:2928-2937.

Godlove DC, Emeric EE, Segovis CM, Young MS, Schall JD, Woodman GF (2011) Event-related potentials elicited by errors during the stop-signal task. I. Macaque monkeys. J Neurosci 31:15640-15649.

Gottlieb J (2007) From thought to action: the parietal cortex as a bridge between perception, action, and cognition. Neuron 53:9-16.

Hanes DP, Schall JD (1996) Neural control of voluntary movement initiation. Science 274:427-430.

Hanes DP, Patterson WF 2nd, Schall JD (1998) Role of frontal eye fields in countermanding saccades: visual, movement, and fixation activity. J Neurophysiol 79:817-834.

Huerta MF, Kaas JH (1990) Supplementary eye field as defined by intracortical microstimulation: connections in macaques. J Comp Neurol 293:299-330.

Huerta MF, Krubitzer LA, Kaas JH (1987) Frontal eye field as defined by intracortical microstimulation in squirrel monkeys, owl monkeys, and macaque monkeys II. Cortical connections. J Comp Neurol 265:332-361.

Ipata AE, Gee AL, Goldberg ME, Bisley JW (2006) Activity in the lateral intraparietal area predicts the goal and latency of saccades in a freeviewing visual search task. J Neurosci 26:3656-3661.

Isoda M, Hikosaka O (2007) Switching from automatic to controlled action by monkey medial frontal cortex. Nat Neurosci 10:240-248.

Isoda M, Hikosaka O (2011) Cortico-basal ganglia mechanisms for overcoming innate, habitual and motivational behaviors. Eur J Neurosci 33:2058-2069.

Itti L, Koch C (2001) Computational modelling of visual attention. Nat Rev Neurosci 2:194-203.

Kastner S, Pinsk MA, De Weerd P, Desimone R, Ungerleider LG (1999) Increased activity in human visual cortex during directed attention in the absence of visual stimulation. Neuron 22:751-761.

Katzner S, Nauhaus I, Benucci A, Bonin V, Ringach DL, Carandini M (2009) Local origin of field potentials in visual cortex. Neuron 61:35-41.

Kristjánsson A, Vuilleumier P, Schwartz S, Macaluso E, Driver J (2007)
Neural basis for priming of pop-out during visual search revealed with fMRI. Cereb Cortex 17:1612-1624.

Lee H, Mozer MC, Vecera SP (2009) Mechanisms of priming of pop-out: stored representations or feature-gain modulations? Atten Percept Psychophys 71:1059-1071.

Logothetis NK, Wandell BA (2004) Interpreting the BOLD signal. Annu Rev Physiol 66:735-769.

Lu X, Matsuzawa M, Hikosaka O (2002) A neural correlate of oculomotor sequences in supplementary eye field. Neuron 34:317-325.

Lui F, Gregory KM, Blanks RH, Giolli RA (1995) Projections from visual areas of the cerebral cortex to pretectal nuclear complex, terminal accessory optic nuclei, and superior colliculus in macaque monkey. J Comp Neurol 363:439-460.

Luppino G, Matelli M, Camarda RM, Gallese V, Rizzolatti G (1991) Multiple representations of body movements in mesial area 6 and the adjacent cingulate cortex: an intracortical microstimulation study in the macaque monkey. J Comp Neurol 311:463-482.

Luppino G, Matelli M, Camarda R, Rizzolatti G (1993) Corticocortical connections of area F3 (SMA proper) and area F6 (pre-SMA) in the macaque monkey. J Comp Neurol 338:114-140.

Lynch JC, Hoover JE, Strick PL (1994) Input to the primate frontal eye field from the substantia nigra, superior colliculus, and dentate nucleus demonstrated by transneuronal transport. Exp Brain Res 100:181-186.

Maljkovic V, Nakayama K (1994) Priming of pop-out: I. Role of features. Mem Cognit 22:657-672.

Matelli M, Luppino G, Rizzolatti G (1991) Architecture of superior and mesial area 6 and the adjacent cingulate cortex in the macaque monkey. J Comp Neurol 311:445-462.

McPeek RM, Keller EL (2001) Short-term priming, concurrent processing, and saccade curvature during a target selection task in the monkey. Vision Res 41:785-800.

McPeek RM, Keller EL (2002) Saccade target selection in the superior colliculus during a visual search task. J Neurophysiol 88:2019-2034.

Mitz AR, Wise SP (1987) The somatotopic organization of the supplementary motor area: intracortical microstimulation mapping. J Neurosci 7:1010-1021.

Mitzdorf U (1985) Current source-density method and application in cat cerebral cortex: investigation of evoked potentials and EEG phenomena. Physiol Rev 65:37-100.

Monosov IE, Trageser JC, Thompson KG (2008) Measurements of simultaneously recorded spiking activity and local field potentials suggest that spatial selection emerges in the frontal eye field. Neuron 57:614-625.

Moore T, Armstrong KM (2003) Selective gating of visual signals by microstimulation of frontal cortex. Nature 421:370-373.

Nakamura K, Roesch MR, Olson CR (2005) Neuronal activity in macaque SEF and ACC during performance of tasks involving conflict. J Neurophysiol 93:884-908.

Ninomiya T, Sawamura H, Inoue K, Takada M (2012) Segregated pathways carrying frontally derived top-down signals to visual areas MT and V4 in macaques. J Neurosci 32:6851-6858.

Okun M, Naim A, Lampl I (2010) The subthreshold relation between cortical local field potential and neuronal firing unveiled by intracellular recordings in awake rats. J Neurosci 30:4440-4448.

Olson CR, Tremblay L (2000) Macaque supplementary eye field neurons encode object-centered locations relative to both continuous and discontinuous objects. J Neurophysiol 83:2392-2411.

Olson CR, Gettner SN, Ventura V, Carta R, Kass RE (2000) Neuronal activity in macaque supplementary eye field during planning of saccades in response to pattern and spatial cues. J Neurophysiol 84:1369-1384.

Paré M, Hanes DP (2003) Controlled movement processing: superior colliculus activity associated with countermanded saccades. J Neurosci 23:6480-6489

Parent A, Hazrati LN (1995) Functional anatomy of the basal ganglia. I. The cortico-basal ganglia-thalamo-cortical loop. Brain Res Rev 20:91-127.

Pouget P, Emeric EE, Stuphorn V, Reis K, Schall JD (2005) Chronometry of visual responses in frontal eye field, supplementary eye field, and anterior cingulate cortex. J Neurophysiol 94:2086-2092.

Pouget P, Stepniewska I, Crowder EA, Leslie MW, Emeric EE, Nelson MJ, Schall JD (2009) Visual and motor connectivity and the distribution of calcium-binding proteins in macaque frontal eye field: implications for saccade target selection. Front Neuroanat 3:2. 
Poulet JF, Petersen CC (2008) Internal brain state regulates membrane potential synchrony in barrel cortex of behaving mice. Nature 454:881-885.

Purcell BA, Schall JD, Logan GD, Palmeri TJ (2012) From salience to saccades: multiple-alternative gated stochastic accumulator model of visual search. J Neurosci 32:3433-3446.

Purcell BP, Heitz RP, Cohen JY, Woodman GF, Schall JD (2010) Timing of attentional selection in frontal eye field and event-related potentials over visual cortex during pop-out search. J Vis 10:97.

Rossi AF, Bichot NP, Desimone R, Ungerleider LG (2007) Top-down attentional deficits in macaques with lesions of lateral prefrontal cortex. J Neurosci 27:11306-11314.

Rushworth MF, Hadland KA, Paus T, Sipila PK (2002) Role of the human medial frontal cortex in task switching: a combined fMRI and TMS study. J Neurophysiol 87:2577-2592.

Russo GS, Bruce CJ (2000) Supplementary eye field: representation of saccades and relationship between neural response fields and elicited eye movements. J Neurophysiol 84:2605-2621.

Sato T, Murthy A, Thompson KG, Schall JD (2001) Search efficiency but not response interference affects visual selection in frontal eye field. Neuron 30:583-591.

Schall JD (1991a) Neuronal activity related to visually guided saccadic eye movements in the supplementary motor area of rhesus monkeys. J Neurophysiol 66:530-558.

Schall JD (1991b) Neuronal activity related to visually guided saccades in the frontal eye fields of rhesus monkeys: comparison with supplementary eye fields. J Neurophysiol 66:559-579.

Schall JD, Boucher L (2007) Executive control of gaze by the frontal lobes. Cogn Affect Behav Neurosci 7:396-412.

Schall JD, Morel A, Kaas JH (1993) Topography of supplementary eye field afferents to frontal eye field in macaque: implications for mapping between saccade coordinate systems. Vis Neurosci 10:385-393.

Schall JD, Morel A, King DJ, Bullier J (1995a) Topography of visual cortex connections with frontal eye field in macaque: convergence and segregation of processing streams. J Neurosci 15:4464-4487.

Schall JD, Hanes DP, Thompson KG, King DJ (1995b) Saccade target selection in frontal eye field of macaque. I. Visual and premovement activation. J Neurosci 15:6905-6918.

Schall JD, Sato TR, Thompson KG, Vaughn AA, Juan CH (2004) Effects of search efficiency on surround suppression during visual selection in frontal eye field. J Neurophysiol 91:2765-2769.

Schiller PH, Chou IH (1998) The effects of frontal eye field and dorsomedial frontal cortex lesions on visually guided eye movements. Nat Neurosci $1: 248-253$.

Schiller PH, Chou I (2000) The effects of anterior arcuate and dorsomedial frontal cortex lesions on visually guided eye movements: 2. Paired and multiple targets. Vision Res 40:1627-1638.

Schiller PH, True SD, Conway JL (1979) Effects of frontal eye field and superior colliculus ablations on eye movements. Science 206:590-592.

Schlag J, Schlag-Rey M (1987) Evidence for a supplementary eye field. J Neurophysiol 57:179-200.

Schlag-Rey M, Amador N, Sanchez H, Schlag J (1997) Antisaccade performance predicted by neuronal activity in the supplementary eye field. Nature 390:398-401.
Schmolesky MT, Wang Y, Hanes DP, Thompson KG, Leutgeb S, Schall JD, Leventhal AG (1998) Signal timing across the macaque visual system. J Neurophysiol 79:3272-3278.

Scudder CA, Kaneko CS, Fuchs AF (2002) The brainstem burst generator for saccadic eye movements: a modern synthesis. Exp Brain Res 142: $439-462$

Seo H, Lee D (2009) Behavioral and neural changes after gains and losses of conditioned reinforcers. J Neurosci 29:3627-3641.

Shen K, Paré M (2007) Neuronal activity in superior colliculus signals both stimulus identity and saccade goals during visual conjunction search. J Vis 7:15.1-15.13.

So NY, Stuphorn V (2010) Supplementary eye field encodes option and action value for saccades with variable reward. J Neurophysiol 104: 2634-2653.

So N, Stuphorn V (2012) Supplementary eye field encodes reward prediction error. J Neurosci 32:2950-2963.

Stuphorn V, Schall JD (2006) Executive control of countermanding saccades by the supplementary eye field. Nat Neurosci 9:925-931.

Stuphorn V, Taylor TL, Schall JD (2000) Performance monitoring by the supplementary eye field. Nature 408:857-860.

Stuphorn V, Brown JW, Schall JD (2010) Role of supplementary eye field in saccade initiation: executive, not direct, control. J Neurophysiol 103 : 801-816.

Sumner P, Nachev P, Morris P, Peters AM, Jackson SR, Kennard C, Husain M (2007) Human medial frontal cortex mediates unconscious inhibition of voluntary action. Neuron 54:697-711.

Thomas NW, Paré M (2007) Temporal processing of saccade targets in parietal cortex area LIP during visual search. J Neurophysiol 97:942-947.

Thompson KG, Bichot NP (2005) A visual salience map in the primate frontal eye field. Prog Brain Res 147:251-262.

Thompson KG, Hanes DP, Bichot NP, Schall JD (1996) Perceptual and motor processing stages identified in the activity of macaque frontal eye field neurons during visual search. J Neurophysiol 76:4040-4055.

Tsotsos JK, Culhane SM, Kei Wai WY, Lai Y, Davis N, Nuflo F (1995) Modeling visual attention via selective tuning. Artif Intell 78:507-545.

Walsh V, Le Mare C, Blaimire A, Cowey A (2000) Normal discrimination performance accompanied by priming deficits in monkeys with $\mathrm{V} 4$ or TEO lesions. Neuroreport 11:1459-1462.

Wardak C, Vanduffel W, Orban GA (2010) Searching for a salient target involves frontal regions. Cereb Cortex 20:2464-2477.

Wolfe JM (2007) Guided search 4.0: current progress with a model of visual search. In: Integrated models of cognitive systems (Gray WD, ed), pp 99-119. New York: Oxford.

Wolfe JM, Butcher SJ, Lee C, Hyle M (2003) Changing your mind: on the contributions of top-down and bottom-up guidance in visual search for feature singletons. J Exp Psychol Hum Percept Perform 29:483-502.

Wyder MT, Massoglia DP, Stanford TR (2004) Contextual modulation of central thalamic delay-period activity: representation of visual and saccadic goals. J Neurophysiol 91:2628-2648.

Yang SN, Hwang H, Ford J, Heinen S (2010) Supplementary eye field activity reflects a decision rule governing smooth pursuit but not the decision. J Neurophysiol 103:2458-2469. 